\title{
Long-Term Exposure to Air Pollution and Incidence of Myocardial Infarction: A Danish Nurse Cohort Study
}

\author{
Johannah Cramer, ${ }^{1}$ Jeanette T. Jørgensen, ${ }^{1}$ Barbara Hoffmann, ${ }^{2}$ Steffen Loft, ${ }^{1}$ Elvira V. Bräuner, ${ }^{3}$ Eva Prescott, ${ }^{4}$ \\ Matthias Ketzel, ${ }^{5,6}$ Ole Hertel, ${ }^{5}$ Jørgen Brandt, ${ }^{5}$ Steen S. Jensen, ${ }^{5}$ Claus Backalarz, ${ }^{7}$ Mette K. Simonsen, ${ }^{8}$ and \\ Zorana J. Andersen ${ }^{1,9}$ \\ ${ }^{1}$ Department of Public Health, Faculty of Health and Medical Sciences, University of Copenhagen, Copenhagen, Denmark \\ ${ }^{2}$ Institute of Occupational, Social and Environmental Medicine, Medical Faculty, Heinrich Heine University, Dusseldorf, Germany \\ ${ }^{3}$ Department of Growth and Reproduction, Rigshospitalet, University of Copenhagen, Copenhagen, Denmark \\ ${ }^{4}$ Department of Clinical Medicine, Faculty of Health and Medical Sciences, Bispebjerg-Frederiksberg Hospital, University of Copenhagen, \\ Copenhagen, Denmark \\ ${ }^{5}$ Department of Environmental Science, Aarhus University, Roskilde, Denmark \\ ${ }^{6}$ Global Centre for Clean Air Research, Department of Civil and Environmental Engineering, University of Surrey, Guildford, UK \\ ${ }^{7}$ Danish Electronics Light \& Acoustics, Hørsholm, Denmark \\ ${ }^{8}$ Diakonissestiftelsen and Parker Institute, Frederiksberg Hospital, Frederiksberg, Denmark \\ ${ }^{9}$ Centre for Epidemiological Research, Nykøbing F. Hospital, Nykøbing Falster, Denmark
}

BaCKGround: Air pollution exposure has been linked to coronary heart disease, although evidence on $\mathrm{PM}_{2.5}$ and myocardial infarction (MI) incidence is mixed.

ОвJECTIVES: This prospective cohort study aimed to investigate associations between long-term exposure to air pollution and MI incidence, adjusting for road traffic noise.

Methods: We used data from the nationwide Danish Nurse Cohort on 22,882 female nurses ( $>44$ years of age) who, at recruitment in 1993 or 1999 , reported information on cardiovascular disease risk factors. Data on MI incidence was collected from the Danish National Patient Register until the end of 2014. Annual mean concentrations of particulate matter (PM) with a diameter $<2.5 \mu \mathrm{g} / \mathrm{m}^{3}\left(\mathrm{PM}_{2.5}\right)$, $\mathrm{PM}_{10}$, nitrogen dioxide (NO 2$)$, and nitrogen oxides $\left(\mathrm{NO}_{\mathrm{x}}\right)$ at the nurses' residences since $1990\left(\mathrm{PM}_{10}\right.$ and $\left.\mathrm{PM}_{2.5}\right)$ or $1970\left(\mathrm{NO}_{2}\right.$ and $\left.\mathrm{NO}_{\mathrm{x}}\right)$ were estimated using the Danish Eulerian Hemispheric Model/Urban Background Model/AirGIS (DEHM/UBM/AirGIS) dispersion model. We used time-varying Cox regression models to examine the association between 1- and 3-y running means of these pollutants, as well as 23-y running means of $\mathrm{NO}_{2}$ and $\mathrm{NO}_{\mathrm{x}}$, with both overall and fatal incident MI. Associations were explored in three progressively adjusted models: Model 1, adjusted for age and baseline year; Model 2, with further adjustment for potential confounding by lifestyle and cardiovascular disease risk factors; and Model 3, with further adjustment for road traffic noise, modeled as the annual mean of a weighted 24 -h average $\left(\mathrm{L}_{\mathrm{den}}\right)$.

RESULTS: Of the 22,882 women, 641 developed MI during a mean follow-up of 18.6 y, 121 (18.9\%) of which were fatal. Reported hazard ratios (HRs) were based on interquartile range increases of 5.3, 5.5, 8.1, and $11.5 \mu \mathrm{g} / \mathrm{m}^{3}$ for $\mathrm{PM}_{2.5}, \mathrm{PM}_{10}, \mathrm{NO}_{2}$, and $\mathrm{NO}_{\mathrm{X}}$, respectively. In Model 1, we observed a positive association between a 3-y running mean of $\mathrm{PM}_{2.5}$ and an overall incident MI with an $\mathrm{HR}=1.20$ (95\% CI: 1.07, 1.35 ), which attenuated to $\mathrm{HR}=1.06(95 \% \mathrm{CI}: 0.92,1.23)$ in Model 2. In Model 1 for incident fatal MI, we observed a strong association with a 3-y running mean of $\mathrm{PM}_{2.5}$, with an $\mathrm{HR}=1.69$ (95\% CI: 1.33, 2.13), which attenuated to $\mathrm{HR}=1.35$ (95\% CI: 1.01, 1.81) in Model 2. Similar associations were seen for $\mathrm{PM}_{10}$, with 3-y, Model 2 estimates for overall and fatal incident MI of HR=1.06 (95\% CI: 0.91, 1.23) and HR=1.35 (95\% CI: $1.01,1.81$ ), respectively. No evidence of an association was observed for $\mathrm{NO}_{2}$ or $\mathrm{NO}_{\mathrm{x}}$. For all pollutants, associations in Model 2 were robust to further adjustment for road traffic noise in Model 3 and were similar for a 1-y running mean exposure.

Conclusions: We found no association between long-term exposure to $\mathrm{PM}_{2.5}, \mathrm{PM}_{10}, \mathrm{NO}_{2}$, or $\mathrm{NO}_{\mathrm{x}}$ and overall MI incidence, but we observed positive associations for $\mathrm{PM}_{2.5}$ and $\mathrm{PM}_{10}$ with fatal MI. We present novel findings that the association between PM and MI incidence is robust to adjustment for road traffic noise. https://doi.org/10.1289/EHP5818

\section{Introduction}

There is growing evidence on the association between long-term exposure to air pollution and cardiovascular disease (CVD) mortality (Faustini et al. 2014; Lelieveld et al. 2019; Pope et al. 2004). Investigations into the association between air pollution and the incidence of specific cardiovascular events, such as myocardial

\footnotetext{
Address correspondence to Z.J. Andersen, Section of Environmental Health, Department of Public Health, University of Copenhagen, Øster Farimagsgade 5, Opgang B, P.O. 2099, 1014 Copenhagen, Denmark. Telephone: 4520740462. Email: zorana.andersen@sund.ku.dk

Supplemental Material is available online (https://doi.org/10.1289/EHP5818).

The authors declare they have no actual or potential competing financial interests

Received 28 June 2019; Revised 16 April 2020; Accepted 17 April 2020; Published 6 May 2020.

Note to readers with disabilities: $E H P$ strives to ensure that all journal content is accessible to all readers. However, some figures and Supplemental Material published in EHP articles may not conform to 508 standards due to the complexity of the information being presented. If you need assistance accessing journal content, please contact ehponline@niehs.nih.gov. Our staff will work with you to assess and meet your accessibility needs within 3 working days.
}

infarction (MI), however, are inconsistent and still under debate. A number of studies have detected significant positive associations between MI incidence and air pollutants such as nitrogen dioxide $\left(\mathrm{NO}_{2}\right)$ (Grazuleviciene et al. 2004; Rosenlund et al. 2009; Roswall et al. 2017) and particulate matter (PM) with a diameter $<2.5 \mu \mathrm{g} / \mathrm{m}^{3}\left(\mathrm{PM}_{2.5}\right)$ (Bai et al. 2019a; Danesh Yazdi et al. 2019; Klompmaker et al. 2019; Madrigano et al. 2013; Yusuf et al. 2020), $<10 \mu \mathrm{g} / \mathrm{m}^{3}\left(\mathrm{PM}_{10}\right)$ (Rosenlund et al. 2009), or $<0.1 \mu \mathrm{g} / \mathrm{m}^{3}$ [ultrafine particles (UFPs)] (Bai et al. 2019b; Downward et al. 2018). However, in many of the aforementioned, and other, studies, associations for $\mathrm{NO}_{2}$ (Atkinson et al. 2013; Bai et al. 2019a, 2019b; Downward et al. 2018; Lipsett et al. 2011; Rosenlund et al. 2006), $\mathrm{PM}_{2.5}$ (Downward et al. 2018; Lipsett et al. 2011; Miller et al. 2007; Puett et al. 2011, 2009), PM 10 (Atkinson et al. 2013; Downward et al. 2018; Klompmaker et al. 2019; Lipsett et al. 2011; Puett et al. 2011, 2008; Rosenlund et al. 2006), and nitrogen oxides $\left(\mathrm{NO}_{\mathrm{x}}\right)$ (Bodin et al. 2016; Downward et al. 2018; Lipsett et al. 2011; Stockfelt et al. 2015) have been null or nonsignificant. Notably, those studies that examined nonfatal and fatal MI incidence separately reported stronger associations with fatal MI for $\mathrm{NO}_{2}$ (Rosenlund et al. 2009, 2006; Roswall et al. 2017) and $\mathrm{PM}_{10}$ (Rosenlund et al. 2009, 2006). This raises questions about the 
mechanisms underlying air pollution-induced MI and may imply that air pollution leads to more severe, or fatal, ischemic events.

Recently, associations between road traffic noise exposure and both MI (Babisch 2014; Selander et al. 2013) and cardiovascular mortality (Heinonen-Guzejev et al. 2007) have been documented. Because road traffic is an important source of both urban air pollution and noise exposure, it is important to take potential confounding or effect modification by road traffic noise exposure into account when assessing the health effects of urban air pollution. Only three studies on air pollution and MI incidence have examined the potential confounding effects by road traffic noise (Bai et al. 2019b; Bodin et al. 2016; Roswall et al. 2017). Roswall et al. (2017) showed that $\mathrm{NO}_{2}$ and road traffic noise were both significantly associated with MI and that mutual exposure adjustment attenuated the association with $\mathrm{NO}_{2}$, but not with noise. Bai et al. (2019b) reported a weak but significant association between UFP exposure and MI that was unchanged following adjustment for road traffic noise, and Bodin et al. (2016) found no evidence of an association between noise or $\mathrm{NO}_{\mathrm{x}}$ with MI. Furthermore, in another recent nationwide Swiss study assessing associations with MI mortality, Héritier et al. (2019) reported that the effects of air pollution were attenuated after adjustment for transportation noise and concluded that air pollution studies not adequately accounting for the effects of transportation noise exposure risk overestimating the cardiovascular disease burden of air pollution.

To date, no single cohort study has assessed the effects of PM in single-pollutant models adjusted for the effects of road traffic noise. In the present study, we aimed to investigate the relationship between long-term exposure to $\mathrm{PM}_{2.5}, \mathrm{PM}_{10}, \mathrm{NO}_{2}$, and $\mathrm{NO}_{\mathrm{x}}$ and incidence of $\mathrm{MI}$, separately for overall and fatal incident MI, while considering the potential attenuating effects of road traffic noise as a confounder.

\section{Methods}

\section{The Danish Nurse Cohort}

Established in 1993, and inspired by the American Nurses' Health Study, the Danish Nurse Cohort was designed to examine the effects of hormone replacement therapy in the Danish population (Hundrup et al. 2012). The Danish Nurse Organization (DNO), comprising both actively working and retired Danish nurses, had a 95\% inclusion rate at the start of the study period and is highly representative of the Danish nursing workforce. In 1993, initial questionnaires were mailed to all 23,170 female DNO members ( $>44$ years of age), to which $19,898(86 \%)$ responded. In 1999, the cohort was reinvestigated and an additional 8,833 (69\%) nurses (either newly invited women who turned 45 years of age in the interim, or re-invited nonresponders from 1993) were included. Upon inclusion, information was collected on working conditions, lifestyle factors (including dietary, physical activity, smoking, and alcohol consumption habits), and various measures of self-reported health, including height, weight, history of various diseases (including cardiovascular), and reproductive health history. In 1999, additional information on lifetime changes in weight and family body type was gathered. All 28,731 female nurses received unique identification numbers, which were then linked to the Danish Civil Registration System (Pedersen 2011) for the collection of vital statistics (date of death or emigration, and full residential address history) between 1970 and whichever of the following came first: date of death, emigration, or disappearance or 31 December 2014.

\section{Outcome Definitions}

Information on MI incidence was obtained by linking the nurses to the Danish National Patient Registry (DNPR), and the Danish
Register of Causes of Death (DRCD) between the baseline (year of cohort entry: 1 April 1993 or 1 April 1999) and end of follow-up on 31 July 2015. The DNPR collects data on both primary and secondary diagnoses affiliated with each hospital contact, registered upon either hospital discharge or completion of an outpatient visit. Established in 1977, and reaching nationwide coverage by 1978 , the DNPR is updated continuously. Between 1982 and 2012, numerous studies have performed a medical record validation of MI as a primary diagnosis in the DNPR and have consistently reported positive predictive values (PPVs) above 90\% (Joensen et al. 2009; Madsen et al. 2003; Sundbøll et al. 2016; Thygesen et al. 2011). In one study, two separate PPVs were calculated for best- and worst-case scenarios. This study reported a 100\% PPV in the best-case scenario based only on assessable or retrievable cases and a 74\% PPV in the worst-case scenario, for which their calculation included those cases deemed insufficient for validation (Coloma et al. 2013). In this study, we categorized MI according to the International Classification of Disease, Eighth Revision (ICD 8; WHO 1966) or the International Statistical Classification of Diseases and Related Health Problems, Tenth Revision (ICD-10; WHO 2016). MI (ICD-8, code 410; ICD-10 code I21) was defined as incident either if it was recorded as a first-time diagnosis between baseline and end of follow-up in the DNPR, or, if it was fatal, as an out-of-hospital MI death in the DRCD (prior to 31 December 2013) if there were no prior DNPR MI diagnoses. Fatal cases of incident MI further included all those who died from any cause within $28 \mathrm{~d}$ following the hospital admission date for an incident MI between baseline and the end of follow-up, as determined from linkage to the Civil Registration System.

\section{Exposure Assignment}

By linking the participants' unique identification numbers, which are administered to all Danish residents through the Danish Civil Registration System, to the Danish Address Database, we collected the geographical coordinates of the participants' residential addresses from 1971 through 31 December 2014. These coordinates were subsequently used to estimate the nurses' residential exposures to both air pollution and road traffic noise.

\section{Assessment of Residential Air Pollution Concentrations}

Annual average exposure levels to $\mathrm{PM}_{2.5}, \mathrm{PM}_{10}, \mathrm{NO}_{2}$, and $\mathrm{NO}_{\mathrm{x}}$ were estimated using the Danish air pollution modeling system Danish Eulerian Hemispheric Model/Urban Background Model/ AirGIS (DEHM/UBM/AirGIS; http://envs.au.dk/en/knowledge/ air/models/airgis/) (Jensen et al. 2017, 2001; Khan et al. 2019), comprising three air pollution models (Brandt et al. 2001). These three models include the DEHM (Brandt et al. 2012; Frohn et al. 2002), which accounts for the long-range transport components, the Danish UBM (Brandt et al. 2012; Frohn et al. 2002), which calculates the local background on a $1-\mathrm{km}^{2}$ resolution grid overlaying Denmark, and the Operational Street Pollution Model (OSPM) (Berkowicz 2000; Ketzel et al. 2012), which estimates the concentration at the residential address' front door. DEHM/ $\mathrm{UBM} /$ AirGIS is a validated air pollution exposure model, and the OSPM utilized for the street-pollution estimates has been employed in over 25 countries (Hvidtfeldt et al. 2018; Ketzel et al. 2012). Comparisons of model results with measurements from the Danish routine monitoring program (comprising 17 stations across the country) show $R^{2}$ values in the range of $0.7-0.9$ depending on site, pollutant, and averaging period (Ellermann et al. 2020). The air pollution exposure modeling system undergoes smaller updates continuously, and for each update careful comparisons with all available measurement data are performed. This study used the annual mean concentrations of $\mathrm{PM}_{2.5}, \mathrm{PM}_{10}$ 
(both available from 1990) $\mathrm{NO}_{2}$ and $\mathrm{NO}_{\mathrm{x}}$ (both available from 1970) at the nurses' residential addresses to comprise 1- and 3-y running means of $\mathrm{PM}_{2.5}, \mathrm{PM}_{10}, \mathrm{NO}_{2}$, and $\mathrm{NO}_{\mathrm{x}}$ as well as 23-y running means of $\mathrm{NO}_{2}$ and $\mathrm{NO}_{\mathrm{x}}$.

\section{Assessment of Residential Road Traffic Noise}

The Nord2000 propagation model (DELTA 2001) was utilized to estimate annual average exposure to road traffic noise at the front doors of the nurses' residential addresses between 1970 and 31 December 2014. The Nord2000 model uses numerous input variables including location geocodes, height of residence, annual average daily traffic information, including traffic characteristics (road types, average speed, composition), building polygons in the surrounding area, and meteorological information (temperature, cloud coverage, wind speed/direction). Estimated as the equivalent A-weighted sound pressure level $\left(\mathrm{LA}_{\mathrm{eq}}\right)$ at the most exposed façade of the residence, annual average road traffic noise levels were estimated independently for the day $\left(\mathrm{L}_{\mathrm{d}} ; 0700-1900\right.$ hours), evening ( $\mathrm{L}_{\mathrm{e}} ; 1900-2200$ hours), and night $\left(\mathrm{L}_{\mathrm{n}} ; 2200-\right.$ 0700 hours) and jointly expressed as $\mathrm{L}_{\mathrm{den}}$, representing noise levels throughout the entire 24-h period. A penalty of 5 and 10 decibels $(\mathrm{dB})$ was added to the evening and night hours, respectively. Annual $\mathrm{L}_{\mathrm{den}}$ means predicted by the Nord2000 propagation model for distances of up to $300 \mathrm{~m}$ have been validated using road test calculations from the European Harmonoise Project. Tests were performed for three cases: $a$ ) propagation over flat grass-covered ground, $b$ ) propagation over a single 6-m high roadside screen, and $c$ ) propagation over a road lined with screens on either side. In all three test cases, the average difference between the reference results and the Nord2000 estimates was $<0.5 \mathrm{~dB}$, with a standard uncertainty of $<1 \mathrm{~dB}$ (DELTA 2006).

\section{Statistical Analyses}

Cox proportional hazards regression models, with age as the underlying timescale, were employed to investigate associations between $\mathrm{PM}_{2.5}, \mathrm{PM}_{10}, \mathrm{NO}_{2}$, and $\mathrm{NO}_{\mathrm{x}}$ and $\mathrm{MI}$ incidence separately for overall and fatal incident MI. Start of follow-up was participant age at cohort entry (as of 1 April 1993 or 1 April 1999), and end of follow-up was whichever of the following came first: date of incident MI (event), date of death, emigration, or 31 July 2015. To discern potential differences between shorter and longer chronic exposures, we investigated the pollutants modeled as the running 1-, 3-, and 23-y means preceding the diagnosis. Exposure windows of 3- and 23-y were selected based on the maximum available data for a given pollutant prior to cohort baseline in 1993. Data on PM was available from 1990 onward, and data on $\mathrm{NO}_{2}$ and $\mathrm{NO}_{\mathrm{x}}$ was available from 1970 onward. For each event (i.e., MI) that occurred during the study, the mean levels of each air pollutant were calculated for the previous 1-, 3-, or 23-y (accounting for all address histories within the given period) and compared with the preceding 1-, 3- or 23-y mean pollutant levels of all other cohort members when they were the same age as the participant at the time of the event. Participants were not excluded if they did not have complete exposure data for 3- or 23-y; their mean exposures were instead calculated based on available data.

In single-pollutant models, we investigated the effects of exposure to 1- and 3-y running means of $\mathrm{PM}_{2.5}, \mathrm{PM}_{10}, \mathrm{NO}_{2}$, and $\mathrm{NO}_{\mathrm{x}}$ and 23-y running means of $\mathrm{NO}_{2}$ and $\mathrm{NO}_{\mathrm{x}}$ using continuous [per increase in interquartile range (IQR)] exposure variables. Due to lack of information, participants who received a stent, underwent a bypass surgery, or experienced other cardiovascular events prior to their MI were not differentiated in the analyses from those who did not. We modeled these associations in three progressively adjusted models: Model 1, adjusted for age (underlying timescale) and year of cohort entry (1993 or 1999); Model 2, further adjusted for potential confounders and CVD risk factors; and Model 3, further adjusted for continuous (per $10 \mathrm{~dB}$ ) residential road traffic noise levels (i.e., $\mathrm{L}_{\mathrm{den}}$ ). Potential confounders and risk factors included smoking status (never/previous/current), number of pack-years, fruit consumption (rarely/few times per week/daily or several times per day), avoidance of fatty meat (yes/no), alcohol consumption in grams (g) per week (never: 0/moderate: 1-14/heavy: <15), physical activity (low/medium/high), marital status (married/ separated/divorced/single/widowed), employment status (working/ home-maker/retired/unemployed or in rehabilitation/other), use of oral contraceptives (ever/never), hormone replacement therapy use (never/previous/current), and level of urbanization (rural/ provincial/urban). Level of urbanization was defined using the following population density thresholds: rural: $<180$ persons $/ \mathrm{km}^{2}$; provincial: $180-185,220$ persons $/ \mathrm{km}^{2}$; urban: $>5,220$ persons $/ \mathrm{km}^{2}$.

Effect modification of the association between a 3-y running mean of residential $\mathrm{PM}_{2.5}$ levels, modeled as a continuous variable, and both overall and fatal incident $\mathrm{MI}$ by age at baseline $(<65 / \geq 65 \mathrm{y})$, road traffic noise $\mathrm{L}_{\mathrm{den}}(<50.4 / 50.4-56.2 / \geq 56.2)$, obesity (yes/no), physical activity (low/medium/high), smoking status (never/previous/current), self-reported hypertension (yes/ no), self-reported diabetes (yes/no), level of urbanization (rural/ provincial/urban), and self-reported menopausal status (pre-/postmenopausal), defined as cessation of bleeding, was assessed through the introduction of interaction terms into the model and tested with log-likelihood tests. In supplemental analyses, we performed the same effect modification analyses for a 1-y running mean of residential $\mathrm{PM}_{2.5}$ levels.

We also conducted several other sensitivity analyses. We evaluated the effect of the following additional variables on the association between air pollution and MI: body mass index (BMI), selfreported diabetes, self-reported hypertension, and average municipality income in 1993 by further adjusting Model 2 for each of these factors independently. We also explored potential calendar effects caused by decreasing exposure levels throughout the study period. In doing so, we assessed pollutant correlations at baseline and at six different time points throughout the study period as well as mean exposure levels for each pollutant throughout the study period. We tested three different methods of adjusting for calendar effects by repeating our 1- and 3-y mean $\mathrm{PM}_{2.5}$ analyses with stratifications on calendar year and birth cohort as well as with adjustment for calendar year as a linear term. As part of this, we examined correlations between each of our pollutants and both calendar year and birth cohort. We further examined the association between air pollution and fatal incident MI, restricted to deaths without prior DNPR MI diagnoses (those identified by the DRCD only), and the impact of individual confounders on the association between air pollution and incident MI by further adjusting Model 1 for each confounder independently.

Deviations from linearity for the association between exposure and outcome for our main analyses were assessed using a likelihood ratio test. Statistical analyses were conducted using Stata (version 14.2; StatCorp) and R (version 3.5.0; R Development Team). Exposure maps were created using features of the Spatial Analyst extension to Esri's ArcMap (version 10.7.1; Esri).

\section{Results}

Of the 28,731 nurses recruited to the Danish Nurse Cohort in either 1993 or 1999, four initial exclusions were made on the basis of inactivity within the Civil Registration System prior to baseline. We excluded an additional 5,552 (19.3\%) nurses with missing information on one or more covariates, potential confounders, or 
Table 1. Descriptive statistics for 22,882 female nurses from the Danish Nurse Cohort at year of cohort entry in 1993 or 1999, by outcome.

\begin{tabular}{|c|c|c|c|c|}
\hline Variables & Total $(n=22,882)$ & MI $(n=22,241)$ & Overall incident MI $(n=641)$ & Fatal incident MI $(n=121)$ \\
\hline$\overline{\text { Age }\{\mathrm{y}[\mathrm{mean}(\mathrm{SD})]\}}$ & $52.8(7.7)$ & $52.6(7.6)$ & $59.2(9.2)$ & $65.0(10.3)$ \\
\hline \multicolumn{5}{|l|}{ Body mass index $\left\{\mathrm{kg} / \mathrm{m}^{2}[n(\%)]\right\}$} \\
\hline Underweight $(<18.5)$ & $553(2.4)$ & $535(2.4)$ & $18(2.8)$ & $4(3.3)$ \\
\hline Overweight (25-30) & $5,214(22.8)$ & $5,033(22.6)$ & $181(28.2)$ & $37(30.6)$ \\
\hline Obese $(\geq 30)$ & $1,295(5.7)$ & $1,246(5.6)$ & $49(7.6)$ & $9(7.4)$ \\
\hline \multicolumn{5}{|l|}{ Smoking status $[n(\%)]$} \\
\hline Current & $7,781(34.0)$ & 7,474 (33.6) & $307(47.9)$ & $66(54.5)$ \\
\hline \multicolumn{5}{|l|}{ Pack-years $[n(\%)]$} \\
\hline Never smoked & $8,224(35.9)$ & $8,054(36.2)$ & $170(26.5)$ & $28(23.1)$ \\
\hline$\leq 10$ & $6,458(28.2)$ & $6,312(28.4)$ & $146(22.8)$ & $24(19.8)$ \\
\hline $11-20$ & $3,723(16.3)$ & $3,596(16.2)$ & $127(19.8)$ & $22(18.2)$ \\
\hline$>20$ & 4,477 (19.6) & $4,279(19.2)$ & $198(30.9)$ & $47(38.8)$ \\
\hline \multicolumn{5}{|l|}{ Alcohol consumption $\{$ drinks/week $[n(\%)]\}$} \\
\hline Medium & $15,273(66.7)$ & $14,834(66.7)$ & $439(68.5)$ & $78(64.5)$ \\
\hline High & $6,155(26.9)$ & $6,017(27.1)$ & $138(21.5)$ & $17(14.0)$ \\
\hline \multicolumn{5}{|l|}{ Fruit consumption $[n(\%)]$} \\
\hline Rarely & $828(3.6)$ & 805 (3.6) & $23(3.6)$ & $6(5.0)$ \\
\hline Few times per week & $6,516(28.5)$ & $6,324(28.4)$ & $192(30.0)$ & $34(28.1)$ \\
\hline Daily or several times per day & $15,538(67.9)$ & $15,112(67.9)$ & $426(66.5)$ & $81(66.9)$ \\
\hline \multicolumn{5}{|l|}{ Avoids fatty meat $[n(\%)]$} \\
\hline No & $2,123(9.3)$ & $2,046(9.2)$ & $77(12.0)$ & $12(9.9)$ \\
\hline Yes & $20,759(90.7)$ & $20,195(90.8)$ & $564(88.0)$ & $109(90.1)$ \\
\hline \multicolumn{5}{|l|}{ Hypertension $[n(\%)]^{a}$} \\
\hline No & $20,054(87.6)$ & $19,592(88.1)$ & $462(72.1)$ & 77 (63.6) \\
\hline Yes & $2,828(12.4)$ & $2,649(11.9)$ & $179(27.9)$ & $44(36.4)$ \\
\hline \multicolumn{5}{|l|}{ Diabetes $[n(\%)]^{a}$} \\
\hline No & $22,628(98.9)$ & $22,008(99.0)$ & $620(96.7)$ & $110(90.9)$ \\
\hline \multicolumn{5}{|l|}{ Oral contraceptive use $[n(\%)]$} \\
\hline Premenopausal & $11,504(50.3)$ & $11,364(51.1)$ & $140(21.8)$ & $15(12.4)$ \\
\hline Postmenopausal & $11,378(49.7)$ & $10,877(48.9)$ & $501(78.2)$ & $106(87.6)$ \\
\hline Employment status $[n(\%)]$ & & & & \\
\hline Actively working & $18,305(80.0)$ & $17,962(80.8)$ & $343(53.5)$ & $38(31.4)$ \\
\hline Homemaker & $407(1.8)$ & $396(1.8)$ & $11(1.7)$ & $2(1.7)$ \\
\hline Retired & $3,808(16.6)$ & $3,527(15.9)$ & $281(43.8)$ & $80(66.1)$ \\
\hline Unemployed/rehabilitation & $149(0.7)$ & $146(0.7)$ & $3(0.5)$ & $1(0.8)$ \\
\hline Other & $213(0.9)$ & $210(0.9)$ & $3(0.5)$ & $0(0.0)$ \\
\hline Marital status $[n(\%)]$ & & & & \\
\hline Married & $16,262(71.1)$ & $15,852(71.3)$ & $410(64.0)$ & $56(46.3)$ \\
\hline Separated & $388(1.7)$ & $379(1.7)$ & $9(1.4)$ & $0(0.0)$ \\
\hline Divorced & $2,593(11.3)$ & $2,531(11.4)$ & $62(9.7)$ & $11(9.1)$ \\
\hline Single & $2,210(9.7)$ & $2,132(9.6)$ & $78(12.2)$ & $30(24.8)$ \\
\hline Widowed & $1,429(6.2)$ & $1,347(6.1)$ & $82(12.8)$ & $24(19.8)$ \\
\hline Urbanization level $[n(\%)]$ & & & & \\
\hline Rural & $9,428(41.2)$ & $9,139(41.1)$ & $289(45.1)$ & $57(47.1)$ \\
\hline Provincial & $9,973(43.6)$ & $9,728(43.7)$ & $245(38.2)$ & $47(38.8)$ \\
\hline Urban & $3,481(15.2)$ & $3,374(15.2)$ & $107(16.7)$ & $17(14.0)$ \\
\hline Average municipality income $\{\text { DKK }[\text { mean (SD) }]\}^{b}$ & $164,487.4(24,855.9)$ & $164,546.4(24,914.5)$ & $162,442.1(22,652.3)$ & $160,236.4(22,208.6)$ \\
\hline Air pollution levels at cohort entry $(1-\mathrm{y} \text { mean })^{c}$ & & & & \\
\hline $\mathrm{PM}_{2.5}$ levels $\left\{\mu \mathrm{g} / \mathrm{m}^{3}[\right.$ mean $\left.(\mathrm{SD})]\right\}$ & $19.6(3.6)$ & $19.6(3.6)$ & $21.0(3.4)$ & $21.5(3.3)$ \\
\hline $\mathrm{PM}_{10}$ levels $\left\{\mu \mathrm{g} / \mathrm{m}^{3}[\right.$ mean (SD) $\left.]\right\}$ & $23.5(3.9)$ & $23.4(3.9)$ & $25.2(3.6)$ & $25.8(3.6)$ \\
\hline $\mathrm{NO}_{2}$ levels $\left\{\mu \mathrm{g} / \mathrm{m}^{3}[\right.$ mean (SD)] $\}$ & $12.6(8.1)$ & $12.6(8.0)$ & $13.6(9.6)$ & $14.2(10.7)$ \\
\hline $\mathrm{NO}_{\mathrm{x}}$ levels $\left\{\mu \mathrm{g} / \mathrm{m}^{3}[\right.$ mean (SD) $\left.]\right\}$ & $19.1(24.4)$ & $19.1(24.2)$ & $22.0(29.7)$ & $24.4(34.9)$ \\
\hline
\end{tabular}


Table 1. (Continued.)

\begin{tabular}{lcccc}
\hline Variables & Total $(n=22,882)$ & MI $(n=22,241)$ & Overall incident MI $(n=641)$ & Fatal incident MI $(n=121)$ \\
\hline Road traffic noise levels at cohort entry $(1-\mathrm{y} \text { mean })^{d, e}$ & & & & \\
$\mathrm{~L}_{\text {den }}\{\mathrm{dB}[\mathrm{mean}(\mathrm{SD})]\}$ & $52.8(8.2)$ & $52.8(8.1)$ & $52.8(8.6)$ & \\
$\mathrm{L}_{\text {den }}\{\mathrm{dB}[n(\%)]\}$ & $7,509(33.1)$ & $7,292(33.0)$ & $217(34.2)$ & $43.1(8.2)$ \\
Low $(<50.4)$ & $7,582(33.4)$ & $7,379(33.4)$ & $203(32.0)$ & $30(34.5)$ \\
Medium $(50.4-56.2)$ & $7,624(33.6)$ & $7,410(33.6)$ & $214(33.8)$ & \\
High $(\geq 56.2)$ & $7,509(33.1)$ & $7,292(33.0)$ & $217(34.2)$ & $40(34.5)$ \\
\hline
\end{tabular}

Note: DKK, Danish Crowns; $\mathrm{L}_{\mathrm{den}}$, joint expression of day $\left(\mathrm{L}_{\mathrm{d}} ; 0700-1900\right.$ hours), evening $\left(\mathrm{L}_{\mathrm{e}} ; 1900-2200\right.$ hours), and night ( $\mathrm{L}_{\mathrm{n}}$; $2200-0700$ hours) road traffic noise levels, with 5 and $10 \mathrm{~dB}$ penalties added to $\mathrm{L}_{\mathrm{e}}$ and $\mathrm{L}_{\mathrm{n}}$, respectively; $\mathrm{MI}$, myocardial infarction; $\mathrm{NO}_{2}$, nitrogen dioxide; $\mathrm{NO}_{\mathrm{x}}$, nitrogen oxides; PM, particulate matter; $\mathrm{PM}{ }_{25}$, PM with an aerodynamic diameter of $<2.5 \mu \mathrm{g} / \mathrm{m}^{3} ; \mathrm{PM}_{10}$, PM with an aerodynamic diameter of $<10 \mu \mathrm{g} / \mathrm{m}^{3} ; \mathrm{SD}$, standard deviation.

${ }^{a}$ Self-reported (diagnosed/medication for).

${ }^{b}$ In 1993.

${ }^{c}$ Among 21,403 participants with available air pollution data at the year of cohort entry.

${ }^{d}$ Among 22,715 participants with available road traffic noise data at the year of cohort entry.

${ }^{e}$ Annual weighted $\left(5 \mathrm{~dB}\right.$ penalty added to $\mathrm{L}_{\mathrm{e}}$ and $10 \mathrm{~dB}$ penalty added to $\left.\mathrm{L}_{\mathrm{n}}\right)$ mean.

effect modifiers and $292(1 \%)$ with missing exposure data, leaving $22,882(79.6 \%)$ for the final main analyses. These 22,882 nurses were followed for an average of $18.6 \mathrm{y}$, during which time there were 641 cases of incident MI of which 121 were fatal (of which 104 did not have a previous DNPR MI diagnosis). Mean age at baseline was $52.8 \mathrm{y}$. Participants who developed an MI during the study period were more likely to be overweight or obese, current and heavy smokers, nondrinkers, less physically active; to consume less fruit and more fatty meat; to have hypertension; to be diabetic, postmenopausal, retired, single or widowed, ever users of contraception; or to live in rural areas. At the start of follow-up, mean residential $\mathrm{PM}_{2.5}, \mathrm{PM}_{10}, \mathrm{NO}_{2}$, and $\mathrm{NO}_{\mathrm{x}}$ levels for the total sample were $19.6,23.5,12.6$, and $19.1 \mu \mathrm{g} / \mathrm{m}^{3}$, respectively, while mean residential road traffic noise levels were $52.8 \mathrm{~dB} \mathrm{~L} \mathrm{~L}_{\mathrm{den}}$, and slightly higher in nurses who developed MI than in those who did not (Table 1). Descriptive statistics for included and excluded participants are presented in Table S1. Nurses who were excluded from the study were on average 5.2 y older than nurses who were included, and they were more likely to be widowed, retired, postmenopausal, never users of oral contraceptives, and hypertensive. Excluded participants were also more likely than included participants to have been current smokers, moderate alcohol consumers, less physically active, and consumers of fatty meat (see Table S1).

The correlations [measured by the Spearman's rank correlation coefficient $(\rho)$ ] between $\mathrm{PM}_{2.5}$ and $\mathrm{NO}_{2}, \mathrm{PM}_{2.5}$ and $\mathrm{L}_{\mathrm{den}}$, and $\mathrm{NO}_{2}$ and $\mathrm{L}_{\mathrm{den}}$, were $0.65,0.36$, and 0.61 , respectively (see Table S2). Correlations were stronger in urban than in provincial and rural areas. Correlations between the pollutants at six different time points between 1990 and 2014 demonstrated that with the exception of those between $\mathrm{PM}_{2.5}$ and $\mathrm{PM}_{10}$, which decreased from 0.71 to 0.60 , correlation coefficients between pollutants did not change over time (see Table S3). Additional temporal trends in exposure (mean pollutant levels) throughout the study period are shown in Figure S1. Maps depicting spatial differences in exposure to each pollutant at baseline are shown in Figure 1. Although $\mathrm{PM}_{2.5}$ and $\mathrm{PM}_{10}$ levels are highly correlated in urban areas (see Table S2), higher levels of $\mathrm{PM}_{2.5}$ in southeastern Denmark and of $\mathrm{PM}_{10}$ along the Danish west coast highlight notable source differences for these pollutants; $\mathrm{PM}_{2.5}$ levels are influenced by secondary pollution from central Europe, and $\mathrm{PM}_{10}$ levels are influenced by sea spray. $\mathrm{NO}_{2}$ and $\mathrm{NO}_{x}$, primarily traffic related, are substantially higher in urban areas (Figure 1).

We observed positive associations between 1- and 3-y running means of $\mathrm{PM}_{2.5}$ and overall incident $\mathrm{MI}$ in our models adjusted for age and baseline year (Model 1) with a hazard ratio (HR) of 1.17 (95\% CI: 1.05, 1.31) and HR $=1.20$ (95\% CI: 1.07 ,
1.35) per IQR increase of $5.3 \mu \mathrm{g} / \mathrm{m}^{3}$, respectively. These were attenuated in models further adjusted for potential confounding by lifestyle factors and CVD risk factors (Model 2) to $\mathrm{HR}=1.05$ (95\% CI: $0.92,1.19)$ and HR $=1.06$ (95\% CI: 0.92, 1.23) (Table 2). For fatal incident MI, we observed strong associations with 1and 3-y means of $\mathrm{PM}_{2.5}$, with $\mathrm{HR}=1.75$ (95\% CI: 1.40, 2.18) and $\mathrm{HR}=1.69$ (95\% CI: $1.33,2.13$ ), respectively, which, in Model 2, were attenuated to HR $=1.47$ (95\% CI: $1.12,1.93)$ and $\mathrm{HR}=1.35$ (95\% CI: 1.01, 1.81), respectively. Model 2 associations between $\mathrm{PM}_{2.5}$ and both overall and fatal incident MI were robust to further adjustment for road traffic noise in Model 3 (Table 2) and seemed not to deviate from linearity (Figure 2).

Similar trends were observed for $\mathrm{PM}_{10}$, with 1- and 3-y mean exposure Model 2 estimates [HRs (95\% CIs)] for overall incident MI: $\mathrm{HR}=1.04(95 \% \mathrm{CI}: 0.92,1.17)$ and $\mathrm{HR}=1.06$ (95\% CI: $0.93,1.20)$ per IQR increase of $5.5 \mu \mathrm{g} / \mathrm{m}^{3}$, respectively. As with $\mathrm{PM}_{2.5}$, stronger associations were observed among the fatal subset, with 1- and 3-y mean exposure estimates of $\mathrm{HR}=1.43(95 \%$ CI: $1.12,1.81)$, and $\mathrm{HR}=1.28$ (95\% CI: 0.98, 1.65), respectively, for Model 2. No evidence of an association was detected for $\mathrm{NO}_{2}$ or $\mathrm{NO}_{\mathrm{x}}$. Model 2 estimates for 1- and 3-y running means of $\mathrm{NO}_{2}$ were $\mathrm{HR}=1.04$ (95\% CI: $0.94,1.16)$ and $\mathrm{HR}=1.05$ (95\% CI: $0.94,1.16)$ per IQR increase of $8.1 \mu \mathrm{g} / \mathrm{m}^{3}$, whereas those for $\mathrm{NO}_{\mathrm{x}}$ were $\mathrm{HR}=1.02(95 \% \mathrm{CI}: 0.97,1.07)$, and $\mathrm{HR}=1.02(95 \%$ CI: $0.98,1.07)$ per IQR increase of $11.5 \mu \mathrm{g} / \mathrm{m}^{3}$, respectively (Table 2). Model 2 associations were robust to further adjustment for BMI, diabetes, hypertension, and average municipality income (see Table S4). However, independent assessment of each of the confounders on the Model 1 association between the pollutants and incident MI showed that employment status was most responsible for the observed attenuation in models further adjusted for potential confounding (see Table S5). Sensitivity analyses restricted to fatal MI events identified through the DRCD produced stronger estimates than analyses based on the entire subset of incident fatal events (see Table S6). Our effect estimates were also sensitive to all three methods of adjustment for calendar effects. For overall incident MI, all three models produced larger effect estimates than our original analyses. For fatal incident MI, the results were inconsistent. The models with continuous adjustment for, and stratification on, calendar year produced smaller effect sizes, whereas the model stratifying on birth cohort produced a larger effect estimate (see Table S7). Strong negative correlations were observed between calendar year and both $\mathrm{PM}_{2.5}$ and $\mathrm{PM}_{10}$, but not with $\mathrm{NO}_{2}, \mathrm{NO}_{\mathrm{x}}$, or $\mathrm{L}_{\mathrm{den}}$, whereas birth cohort (in 5-y strata) was not correlated with any of the exposure variables (see Table S8).

We found effect modification of the association between a 3-y running mean of $\mathrm{PM}_{2.5}$ and overall incident $\mathrm{MI}$ by diabetes, with a 
A

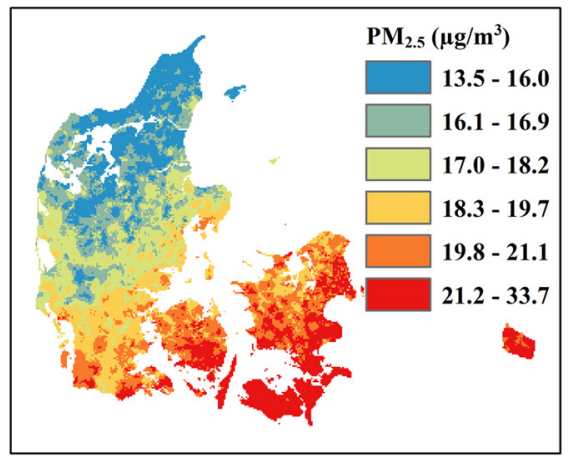

$\mathrm{C}$

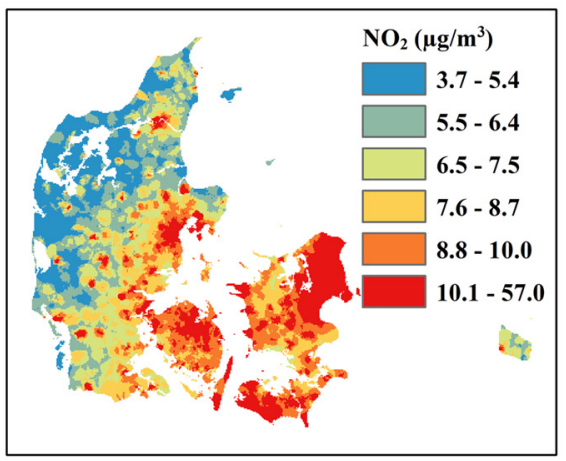

$\mathrm{B}$

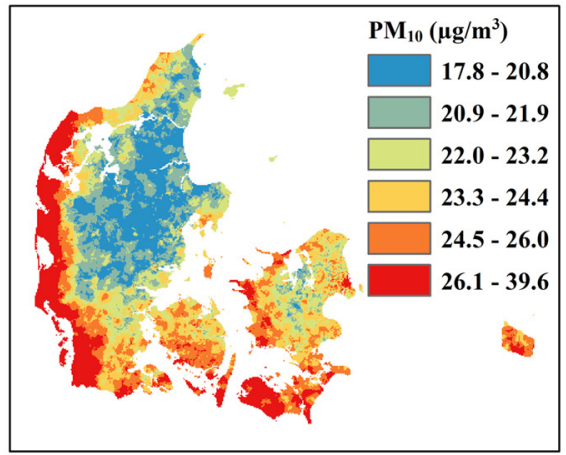

D

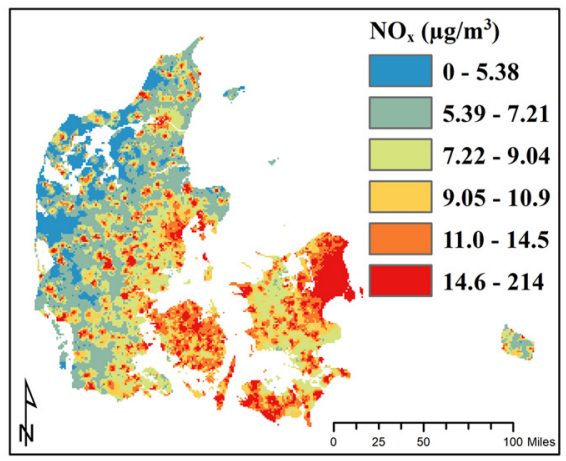

Figure 1. Smoothed maps of annual residential exposure levels for (A) $\mathrm{PM}_{2.5}$, (B) $\mathrm{PM}_{10}$, (C) $\mathrm{NO}_{2}$, and (D) $\mathrm{NO}_{\mathrm{x}}$ in the Danish Nurse Cohort at year of cohort entry (1993 or 1999). Note: $\mathrm{NO}_{2}$, nitrogen dioxide; $\mathrm{NO}_{\mathrm{x}}$, nitrogen oxides; $\mathrm{PM}$, particulate matter; $\mathrm{PM}_{2.5}, \mathrm{PM}$ with a diameter $<2.5 \mu \mathrm{g} / \mathrm{m}^{3} ; \mathrm{PM} 10, \mathrm{PM}$ with a diameter $<10 \mu \mathrm{g} / \mathrm{m}^{3}$.

strong positive association among those with diabetes $[\mathrm{HR}=2.15$ (95\% CI: 1.08, 4.25)] and no association in those without $[\mathrm{HR}=1.02(95 \% \mathrm{CI}: 0.88,1.18)]\left(p_{\text {interaction }}=0.04\right)($ Table 3$)$.
Effect modification analyses using a 1-y running mean of $\mathrm{PM}_{2.5}$ were very similar to those based on the $3-y$ running mean (see Table S9).

Table 2. Associations between long-term exposure to air pollution (per IQR exposure increment) and both overall and fatal incident MI in the Danish Nurse Cohort.

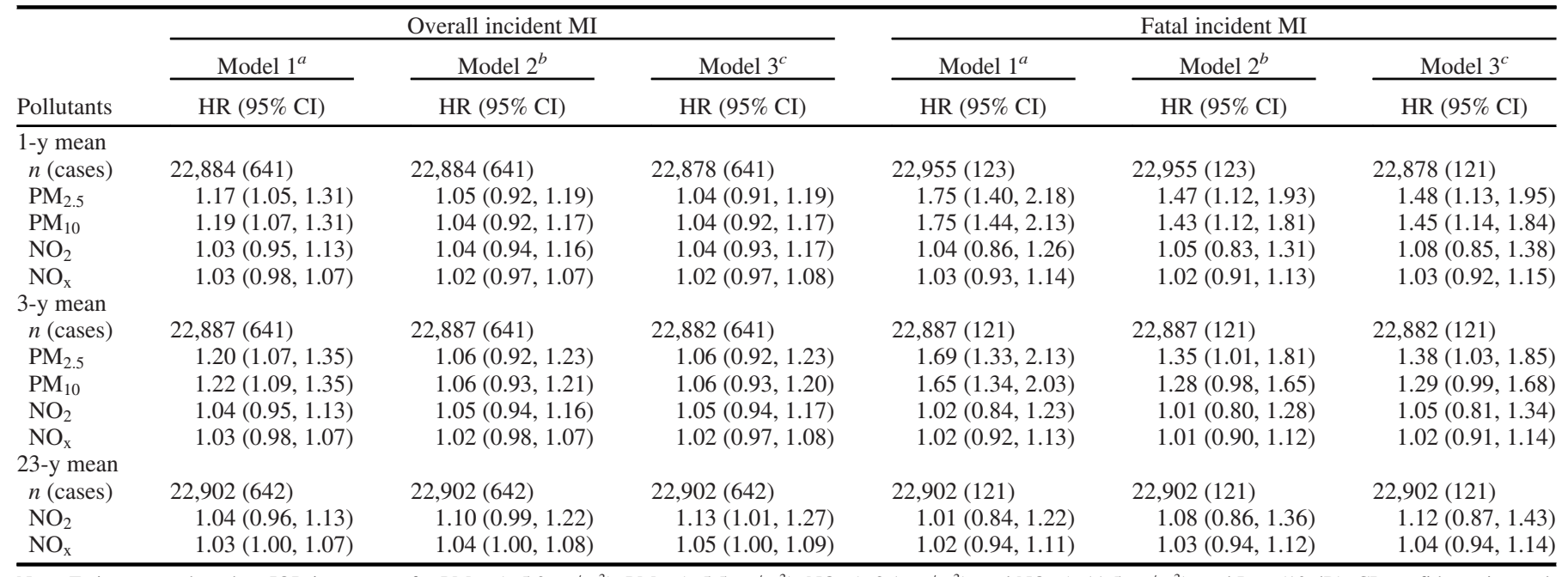

Note: Estimates are based on IQR increments for $\mathrm{PM}_{2.5}\left(<5.3 \mu \mathrm{g} / \mathrm{m}^{3}\right), \mathrm{PM}_{10}\left(<5.5 \mu \mathrm{g} / \mathrm{m}^{3}\right), \mathrm{NO}_{2}\left(<8.1 \mu \mathrm{g} / \mathrm{m}^{3}\right)$, and NO $\mathrm{NO}_{\mathrm{x}}\left(<11.5 \mu \mathrm{g} / \mathrm{m}^{3}\right)$, and $\mathrm{L}_{\mathrm{den}}(10 \mathrm{~dB})$. CI, confidence interval; HR, hazard ratio; IQR, interquartile range; $\mathrm{L}_{\mathrm{den}}$, joint expression of day ( $\mathrm{L}_{\mathrm{d}} ; 0700-1900$ hours), evening $\left(\mathrm{L}_{e} ; 1900-2200\right.$ hours), and night ( $\mathrm{L}_{n} ; 2200-0700$ hours) road traffic noise levels, with 5 and $10 \mathrm{~dB}$ penalties added to $\mathrm{L}_{\mathrm{e}}$ and $\mathrm{L}_{\mathrm{n}}$, respectively; $\mathrm{MI}$, myocardial infarction; $\mathrm{NO}_{2}$, nitrogen dioxide; $\mathrm{NO}_{\mathrm{x}}$, nitrogen oxides; $\mathrm{PM}$, particulate matter; $\mathrm{PM}_{2.5}$, $\mathrm{PM}$ with an aerodynamic diameter of $<2.5 \mu \mathrm{g} / \mathrm{m}^{3} ; \mathrm{PM}_{10}, \mathrm{PM}$ with an aerodynamic diameter of $<10 \mu \mathrm{g} / \mathrm{m}^{3}$.

${ }^{a}$ Model 1: adjusted for age (underlying time) and year of cohort entry (1993 or 1999).

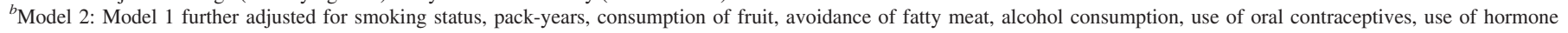
therapy, physical activity, marital status, employment status, and level of urbanization.

${ }^{c}$ Model 3: Model 2 further adjusted for $\mathrm{L}_{\mathrm{den}}$. 
A

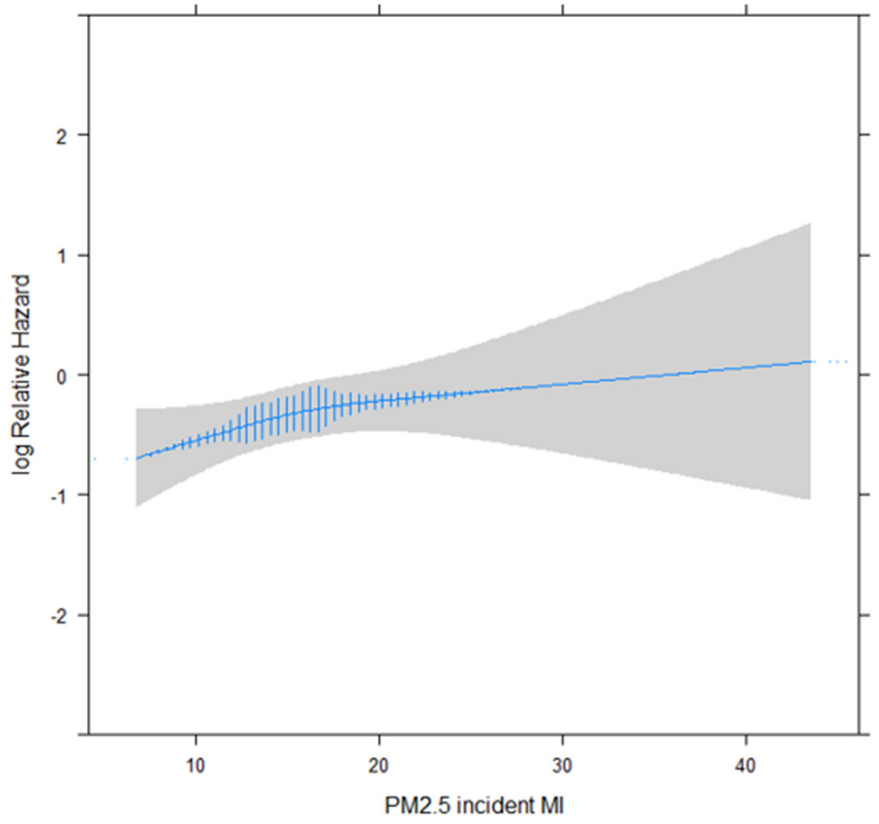

B

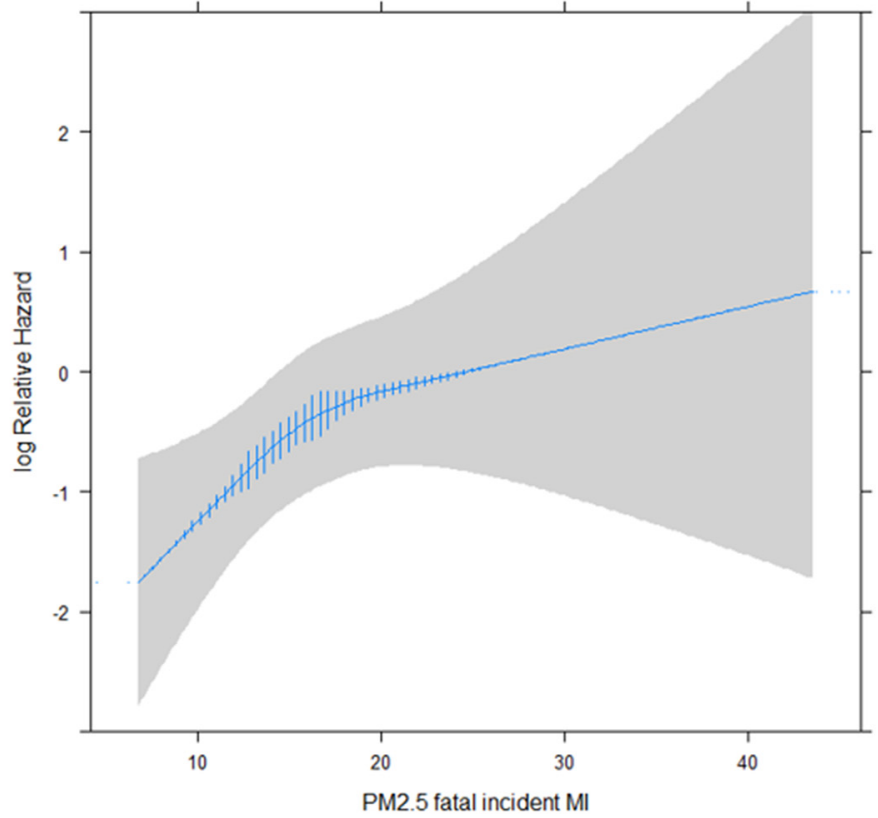

Figure 2. Association between a 3-y running mean of $\mathrm{PM}_{2.5}$ and (A) overall incident $\mathrm{MI}$ and (B) fatal incident MI among study participants, with adjustment for age (underlying time), year of cohort entry (1993 or 1999), smoking status, pack-years, consumption of fruit, avoidance of fatty meat, alcohol consumption, use of oral contraceptives, use of hormone therapy, physical activity, marital status, employment status, and level of urbanization. Vertical blue lines represent the frequency distribution of $\mathrm{PM}_{2.5}$ exposure among the study participants. Note: $\mathrm{MI}$, myocardial infarction; $\mathrm{PM}_{2.5}$, particulate matter with an aerodynamic diameter $<2.5 \mu \mathrm{g} / \mathrm{m}^{3}$.

\section{Discussion}

In this cohort of female Danish nurses $>44$ years of age, we found strong positive associations between long-term exposure to residential $\mathrm{PM}_{2.5}$ and $\mathrm{PM}_{10}$ and the development of fatal $\mathrm{MI}$, but we did not observe associations with overall incident MI for any pollutant. These associations were robust to adjustment for road traffic noise.

We detected strong associations of fatal incident MI with $\mathrm{PM}_{2.5}$ and $\mathrm{PM}_{10}$ but none with $\mathrm{NO}_{2}$ or $\mathrm{NO}_{\mathrm{x}}$. These results are similar to those of Rosenlund et al. $(2009,2006)$ who reported stronger associations between $\mathrm{PM}_{10}$ and fatal $\mathrm{MI}$ than with all incident MI. In another Danish prospective cohort study, Roswall et al. (2017) observed stronger associations between $\mathrm{NO}_{2}$ and fatal incident $\mathrm{MI}$, as compared with all incident MI, and other studies have also reported stronger associations with fatal, compared with nonfatal, cardiovascular outcomes. Puett et al. (2008) detected enhanced associations between $\mathrm{PM}_{10}$ and fatal coronary heart disease (CHD) as compared with overall incident CHD, and Miller et al. (2007) detected stronger associations between $\mathrm{PM}_{2.5}$ and cardiovascular mortality than with $\mathrm{PM}_{2.5}$ and first cardiovascular event. Our findings are also in line with a large body of evidence supporting links between air pollution and cardiovascular mortality (Brook et al. 2010; Hoek et al. 2002; Lelieveld et al. 2019). Together, these findings support the premise that air pollution may be more strongly associated with fatal cardiovascular events. This could be because air pollution is associated with more severe cardiovascular events, fewer MIs that can be treated upon admission, or more out-ofhospital deaths. However, limitations in the quality of cause-ofdeath data for out-of-hospital sudden MI deaths among people with no prior MI diagnoses warrant caution in the interpretation of our findings among the subset of fatal cases.

There are a number of known and suspected biological mechanisms involved in the pathogenesis of air pollution-induced cardiovascular events (Brook et al. 2010). In brief, they include direct effects on both the pulmonary and cardiovascular systems, as well as indirect effects, all of which operate through chronic and systemic inflammatory pathways. Recently it has been suggested that air pollution, acting through inflammatory pathways, may promote cardiovascular events, such as MIs, by triggering vulnerable plaque and increasing thrombogenicity (Xu et al. 2019). Because exposure to both short- (Xu et al. 2019) and long- (Lucht et al. 2019) term air pollution has been associated with markers of such inflammation, including C-reactive protein (Lucht et al. 2019; Xu et al. 2019) and fibrinogen (Xu et al. 2019), it is difficult to discern the exact timescales on which these mechanisms operate.

Animal and human studies suggest the progression of atherosclerosis (a condition promoted by inflammation) as a main mechanism behind air pollution-induced MI and CHD development (Brook et al. 2010; Sun et al. 2005). Associations between air pollution and subclinical atherosclerosis support this (Kaufman et al. 2016; Künzli et al. 2010; Sun et al. 2005). Although the lack of observed effects for any pollutant on overall MI incidence in multiple large epidemiological studies is noteworthy (Atkinson et al. 2013; Bodin et al. 2016; Lipsett et al. 2011; Miller et al. 2007; Puett et al. 2011, 2009, 2008; Rosenlund et al. 2006; Stockfelt et al. 2015), recent evidence of an association between those particles capable of entering the bloodstream, $\mathrm{PM}_{2.5}$ (Bai et al. 2019a; Danesh Yazdi et al. 2019; Klompmaker et al. 2019; Yusuf et al. 2020) and UFPs (Bai et al. 2019b; Downward et al. 2018), and incident MI supports this mechanistic evidence. This may imply that air pollution-promoted atherosclerosis leads to a more severe subtype of ischemic event that results in death. Stronger associations have generally been observed with stroke than with MI (Miller et al. 2007) and other coronary events (Hoffmann et al. 2015), which supports this. Alternatively, advancements in early diagnosis and treatment may result in more angioplasties, which subsequently prevent MI. Interestingly, Miller et al. (2007) found that $\mathrm{PM}_{2.5}$ was positively associated with coronary revascularizations. Rather than air pollution causing more severe cardiovascular events, another 
Table 3. Effect modification of the association between residential $\mathrm{PM}_{2.5}$ concentration (modeled as a continuous variable, 3-y mean, per IQR increase) and both overall and fatal incident MI in the Danish Nurse Cohort.

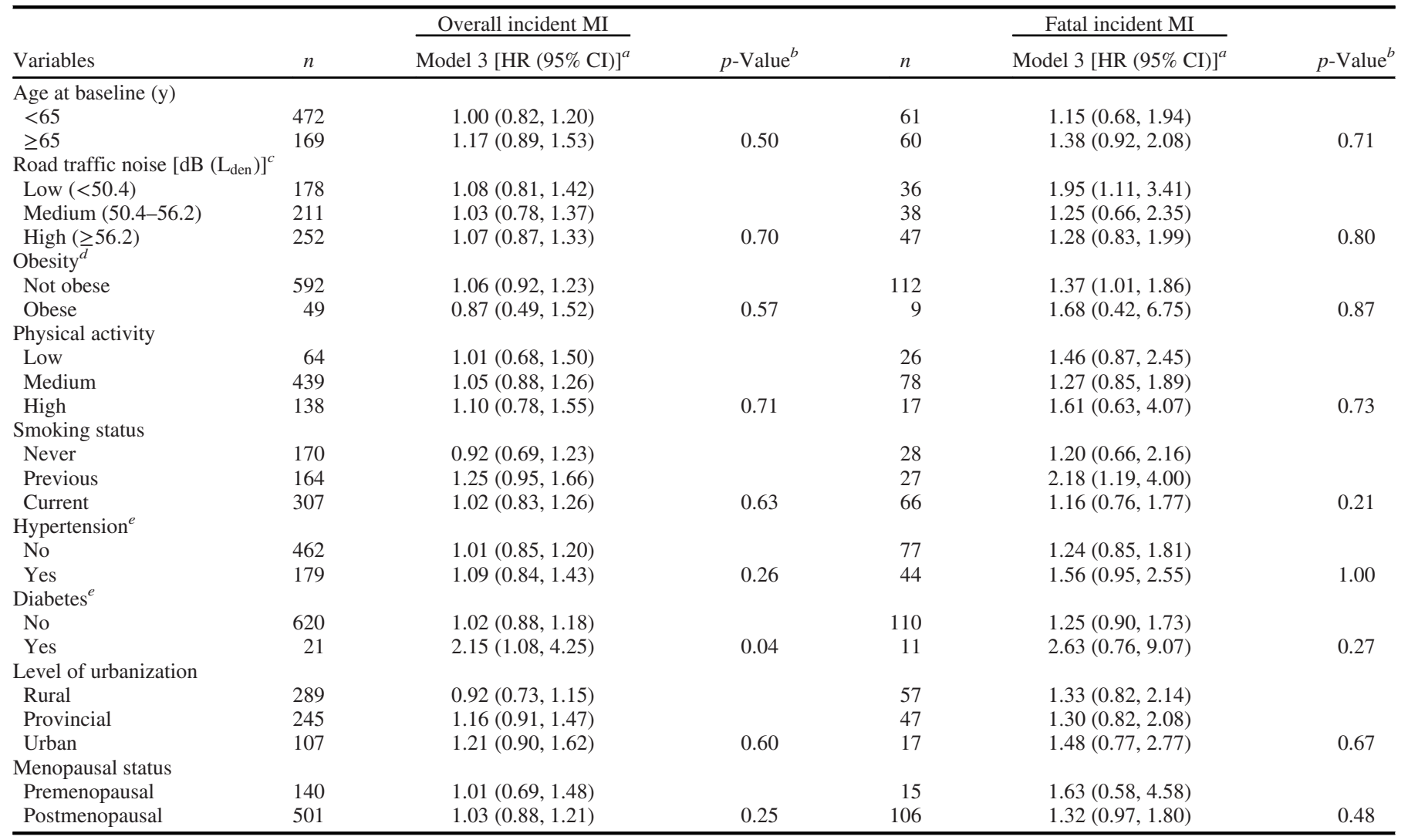

Note: Estimates are based on IQR increments of $5.3 \mu \mathrm{g} / \mathrm{m}^{3}$. CI, confidence interval; HR, hazard ratio; IQR, interquartile range; $\mathrm{L}_{\mathrm{den}}$, joint expression of day ( $\mathrm{L}_{\mathrm{d}}$; 0700-1900 hours), evening ( $\mathrm{L}_{\mathrm{e}} ; 1900-2200$ hours), and night ( $\mathrm{L}_{\mathrm{n}} ; 2200-0700$ hours) road traffic noise levels, with 5 and 10 dB penalties added to $\mathrm{L}_{\mathrm{e}}$ and $\mathrm{L}_{\mathrm{n}}$, respectively; MI, myocardial infarction; $\mathrm{PM}_{2.5}$, particulate matter with an aerodynamic diameter of $<2.5 \mu \mathrm{g} / \mathrm{m}^{3}$.

${ }^{a}$ Model 3 was adjusted for age (underlying time), year of cohort entry (1993 or 1999), smoking status, pack-years, consumption of fruit, avoidance of fatty meat, alcohol consumption, use of oral contraceptives, use of hormone therapy, physical activity, marital status, employment status, level of urbanization, and $\mathrm{L}_{\mathrm{den}}$.

${ }^{b}$ From likelihood ratio test for interaction.

${ }^{c}$ Based on Model 2: (Model 3, unadjusted for $\mathrm{L}_{\mathrm{den}}$ ).

${ }^{d}$ Body mass index $\geq 30$.

${ }^{e}$ Self-reported (diagnosed/medication for).

possible explanation could be that the relatively weak association between these is now masked by better secondary or tertiary prevention and early therapy. This could be, in part, due to the fact that MI has more clinical precursors, such as angina, which facilitate earlier hospital contacts. Air pollution also likely acts through multiple mechanisms and may exacerbate preexisting cardiovascular conditions to contribute to the development of cardiovascular events, fatal or otherwise (Brook et al. 2004; Mann et al. 2002). However, we did not find effect modification of the association between a 3-y mean exposure to $\mathrm{PM}_{2.5}$ and either overall or fatal incident MI by self-reported hypertension, which may be considered a proxy and/or precursor for other cardiovascular conditions. Nurses with hypertension or other cardiovascular conditions may seek out medical monitoring and/or treatment that ultimately prevents MI, or at least prevents severe, fatal MI, possibly explaining this. We did find effect modification of this association by selfreported diabetes, which is in line with a large body of epidemiological evidence suggesting associations between exposure to air pollution and diabetes (Balti et al. 2014), especially among women (Eze et al. 2015; Shin et al. 2019), and supported by experimental evidence of biological links between systemic inflammation and impaired glucose metabolism (Sun et al. 2009).

Although the single validation study of MI in the DRCD suggests that MI as an underlying or contributory cause of death is reliable (Madsen et al. 2003), this validation was predominantly based on cases for which hospital records of an MI exist, as opposed to cases for which autopsy results were available. The autopsy rate in Denmark has dropped from $75 \%$ (of all in-hospital deaths) in the 1970s, to $<10 \%$ by 2011 (Helweg-Larsen 2011), suggesting a decline in the quality of data in the DRCD that should not be overlooked. It is also likely that the stronger associations among fatal cases of incident MI observed in the two Swedish case-control studies (Rosenlund et al. 2009, 2006) suffer from this same limitation. In the Danish Diet, Cancer, and Health cohort, Roswall et al. (2017) observed associations between a 5-y running mean exposure of $\mathrm{NO}_{2}$ and both incident $[\mathrm{HR}=1.07$ (95\% CI: 1.02, 1.11) per $\left.6.8 \mu \mathrm{g} / \mathrm{m}^{3}\right]$ and fatal incident $[\mathrm{HR}=1.15(95 \% \mathrm{CI}: 1.06,1.26) \mathrm{per}$ $7.0 \mu \mathrm{g} / \mathrm{m}^{3}$ ] MI and similar findings for exposure windows of 1and 10-y running means. Although we used the same exposure estimation model in our own study, we did not observe associations for $\mathrm{NO}_{2}$ for any exposure window investigated, among either outcome. There are notable differences between the study by Roswall et al. (2017) and ours, including the populations sampled (urban vs. nationwide) and the defining criteria for cases of fatal incident MI. Despite these differences, the large estimate discrepancies observed between two Danish studies is stark and warrants further prospective cohort investigations into the differential effects of air pollution on severity of $\mathrm{MI}$ in other populations.

Of the recent studies on long-term exposure to $\mathrm{PM}_{2.5}$ and incident MI, three prospective cohort studies (Bai et al. 2019a; 
Danesh Yazdi et al. 2019; Yusuf et al. 2020) observed an association, whereas one (Downward et al. 2018) did not. Among 5.1 million long-term residents of Ontario, a 3-y running mean exposure to $\mathrm{PM}_{2.5}$ was associated with hospital-admission based acute MI incidence $[\mathrm{HR}=1.05$ (95\% CI: 1.04, 1.06), per $3.5 \mu \mathrm{g} / \mathrm{m}^{3}$ ] (Bai et al. 2019a). A 3-y running mean exposure to $\mathrm{PM}_{2.5}$ was also associated with MI incidence [HR $=1.03(95 \%$ CI: $1.00,1.06)$, per $\left.10 \mu \mathrm{g} / \mathrm{m}^{3}\right]$ in the Prospective Urban and Rural Epidemiology cohort, based on 21 countries and 155,722 participants (Yusuf et al. 2020). Among Medicare participants in seven southeastern states in the United States, each $1-\mu \mathrm{g} / \mathrm{m}^{3}$ increase in annual mean $\mathrm{PM}_{2.5}$ concentration was associated with first hospital MI admission [HR = 1.026 (95\% CI: 1.024, 1.028)] (Danesh Yazdi et al. 2019). Our $\mathrm{PM}_{2.5}$ estimate for the 3-y running mean $[\mathrm{HR}=1.06$ (95\% CI: $0.92,1.23)$ per $\left.5.3 \mu \mathrm{g} / \mathrm{m}^{3}\right]$ is of a similar effect size to the 3-y mean estimates reported by Bai et al. (2019a) and Yusuf et al. (2020), and we believe our estimates are more in line with the results from these studies than those from Downward et al. (2018), who reported a nonsignificant, although inverse, association between $\mathrm{PM}_{2.5}$ and incident MI $\left[\mathrm{HR}=0.83(95 \%\right.$ CI: $0.44,1.57)$ per $\left.5 \mu \mathrm{g} / \mathrm{m}^{3}\right]$ among the Dutch branch of the European Prospective Investigation into Cancer and Nutrition study (Downward et al. 2018). However, Downward et al. (2018) also reported associations with both $\mathrm{PM}_{\text {coarse }}(\mathrm{PM}$ with an aerodynamic diameter of 2.5-10 $\mu \mathrm{m})$ and UFPs (Downward et al. 2018), supporting the need for further investigation into different size fractions of PM.

Our findings also corroborate those from earlier large cohort and case-control studies (Lipsett et al. 2011; Madrigano et al. 2013; Miller et al. 2007; Puett et al. 2011, 2009). Among 65,893 women in the Women's Health Initiative cohort, Miller et al. (2007) detected associations between long-term exposure to $\mathrm{PM}_{2.5}$ and incidence of overall cardiovascular disease as well as CHD, cerebrovascular disease, stroke, and coronary revascularization but not MI incidence [HR $=1.06$ (95\% CI: $0.85,1.34)$ per $\left.10 \mu \mathrm{g} / \mathrm{m}^{3}\right]$. In the California Teacher's Study (124,614 women), Lipsett et al. (2011) found no association between MI incidence and $\mathrm{PM}_{2.5}\left[\mathrm{HR}=0.98\right.$ (95\% CI: $0.83,1.16$ per $\left.\left.10 \mu \mathrm{g} / \mathrm{m}^{3}\right)\right]$ nor $\mathrm{PM}_{10}, \mathrm{NO}_{2}$, or $\mathrm{NO}_{\mathrm{x}}$. In line with our findings, Madrigano et al. (2013) detected associations with area-level $\mathrm{PM}_{2.5}$, but none with total $\mathrm{PM}_{2.5}$, in a case-control study based on 4,467 MI cases from the Worcester Heart Attack Study [odds ratio $(\mathrm{OR})=1.04$ (95\% CI: $0.96,1.11)$ per $\left.1.05 \mu \mathrm{g} / \mathrm{m}^{3}\right]$. The majority of studies on long-term exposure to $\mathrm{PM}_{2.5}$, including this one, suggest that the evidence for an association with incident MI is weak. However, given that a number of recent studies that may benefit from improved exposure modeling methods, have found evidence for an association, and given that the suggestion of an association with fatal incident MI, there is still a need to further explore these relationships. Because $\mathrm{PM}_{10}$ is partially comprised of $\mathrm{PM}_{2.5}$ and because these two pollutants are moderately correlated throughout our study period (see Table S3), we cannot fully separate the effects of each of these pollutants. However, it remains useful to compare our $\mathrm{PM}_{10}$ estimates with those from other studies. In line with the majority of studies on $\mathrm{PM}_{10}$ (Atkinson et al. 2013; Downward et al. 2018; Klompmaker et al. 2019; Lipsett et al. 2011; Puett et al. 2011, 2008; Rosenlund et al. 2006), we did not observe evidence of an association with incident MI. For an association between $\mathrm{PM}_{10}$ and incident MI, Downward et al. (2018) reported an $\mathrm{HR}=1.27$ (95\% CI: $0.77,2.09)$ per $10 \mu \mathrm{g} / \mathrm{m}^{3}$. Atkinson et al. (2013) reported an $\mathrm{HR}=1.01$ (95\% CI: 0.98 , 1.05) per $3 \mu \mathrm{g} / \mathrm{m}^{3}$ among 836,557 British general practice patients. Puett et al. (2008) reported an HR $=1.09$ (95\% CI: 0.92, 1.29) per $10 \mu \mathrm{g} / \mathrm{m}^{3}$ among 66,250 nurses from the American Nurses' Health Study, and in a later study on 17,545 male health professionals in the Health Professionals Follow-Up Study, Puett et al. (2011) reported an $\mathrm{HR}=1.05$ (95\% CI: 0.92, 1.22) per $7 \mu \mathrm{g} / \mathrm{m}^{3}$. Further, Rosenlund et al. $(2009,2006)$ reported ORs $(95 \% \mathrm{CI})$ of $1.00(0.79,1.27)$ and $1.04(1.00,1.09)$ per $5 \mu \mathrm{g} / \mathrm{m}^{3}$ in two Swedish case-control studies with 1,397 and 24,347 MI cases, respectively.

Finally, we observed no evidence of an association between $\mathrm{MI}$ incidence and $\mathrm{NO}_{2}$ or $\mathrm{NO}_{\mathrm{x}}$. These findings corroborate those of the majority of studies that have explored long-term exposure to either of these pollutants (Atkinson et al. 2013; Bai et al. 2019a, 2019b; Bodin et al. 2016; Downward et al. 2018; Lipsett et al. 2011; Puett et al. 2008; Rosenlund et al. 2009, 2006; Roswall et al. 2017; Stockfelt et al. 2015), although they are inconsistent with two that detected significant positive associations with $\mathrm{NO}_{2}$ (Grazuleviciene et al. 2004; Roswall et al. 2017). To date, no study has observed an association between long-term exposure to $\mathrm{NO}_{\mathrm{x}}$ and incident MI. Of the studies on $\mathrm{NO}_{2}$, three in particular (Bai et al. 2019a, 2019b; Roswall et al. 2017) serve as useful comparators owing to similarities in exposure estimation methods and statistical modeling techniques. For exposure to $3-y$ running means, Bai et al. $(2019 \mathrm{a}, 2019 \mathrm{~b})$ reported $\mathrm{HR}=1.01$ (95\% CI: 0.99, 1.02) per $13.9 \mathrm{ppb}$ (Bai et al. 2019a) and $\mathrm{HR}=1.01(95 \% \mathrm{CI}: 0.99,1.03)$ per $4.0 \mathrm{ppb}$ (Bai et al. 2019b) among residents throughout the entirety of Ontario and its capital city Toronto, respectively. The effect sizes of these estimates are similar to that in our Model 2 of a 3-y running mean exposure $\left[\mathrm{HR}=1.05(95 \% \mathrm{CI}: 0.94,1.16)\right.$ per $\left.8.1 \mu \mathrm{g} / \mathrm{m}^{3}\right]$. As previously discussed, our study has a number of similarities to the study by Roswall et al. (2017) of the Danish Diet, Cancer and Health cohort, including the air pollution estimation methods, the use of running exposure means, and case indentification methods (for overall incident MI), and it is unclear why Roswall et al. (2017) observed associations with incident and fatal incident MI for 1-, $5-$, and 10-y running means of $\mathrm{NO}_{2}$, whereas we did not. As a major source of $\mathrm{NO}_{2}$ exposure is road traffic, it is possible that Roswall et al. (2017) were better able to detect associations with incident MI among the urban Danish Diet, Cancer and Health cohort. The only other study to report an association between long-term exposure to $\mathrm{NO}_{2}$ and incident $\mathrm{MI}$ was also based on an urban population (Grazuleviciene et al. 2004). Although all other studies have reported null associations, only one has been based on an urban population (Bai et al. 2019b), and it would be interesting to explore the effects of $\mathrm{NO}_{2}$ and $\mathrm{NO}_{\mathrm{x}}$ further among populations that may be prone to higher exposures. Our sensitivity analyses exploring the effects of BMI, self-reported diabetes and hypertension, and average municipality income (Models 4-7; see Table S4) did not deviate substantially from our Models 2 or 3 (Table 2), which were further adjusted for exposure to road traffic noise. Knowledge of the effect of noise exposure on the association between air pollution and incident MI is limited: Although our results support one recent study that found that the association between UFPs and MI was unchanged following adjustment for noise (Bai et al. 2019b), they are less consistent with a large Swiss study that found substantial attenuation of the association between air pollution and MI mortality after adjusting for noise (Héritier et al. 2019). Moreover, we did not see any difference in effect estimates following adjustment for municipality-level income (see Table S4). However, we cannot exclude the possibility of residual confounding by unmeasured spatial factors related to one's neighborhood, such as green space or special emissions sources, which may be uniquely tied to socioeconomic status, and our inability to adjust for these factors is a notable limitation.

The question of which timescale is best to use for Cox models in time-varying air pollution studies and how best to account for calendar effects remains unresolved. Our sensitivity analyses 
testing different methods of controlling for these effects produced HRs for associations with $\mathrm{PM}_{2.5}$ that were substantially larger than those in our main analyses, although confidence intervals between these and our main estimates were overlapping (see Table S7). In their performance assessment of Cox models with different timescales used to study time-varying environmental exposures, Griffin et al. (2012) reported that in cases where the environmental exposure was highly correlated with calendar time, models performed worse when calendar time was either used as the underlying timescale or adjusted for as a covariate when using age or time on study as the underlying scale. Given strong inverse correlations between both $\mathrm{PM}_{2.5}$ and $\mathrm{PM}_{10}$ and calendar year during our study period (see Table S8), we believe the associations from the models adjusting for, and stratifying on, calendar year, are likely an artifact of collinearity. Furthermore, Griffin et al. (2012) noted that models fit with age as the underlying timescale, which did not adjust for calendar time, remained relatively robust. Therefore, we do not believe that secular trends in our exposures are likely to be causing a bias in our original models, despite the lack of adjustment for calendar effects. It has also been suggested that for outcomes in which the effect of age on one's hazard is strong, the best method of controlling for calendar effects is through the use of age as the underlying timescale with stratification on birth cohort (Korn et al. 1997). In our models stratified on birth cohort, we saw an increase in estimate size relative to our original models (see Table S7) although correlation between all our pollutants and birth cohort was low (see Table S8). Because our original estimates were the lowest of any of models adjusting for calendar effects, we believe it is unlikely that the lack of adjustment for calendar effects has induced an association in these models. However, given these findings, the impact of different methods of calendar-effect adjustment on effect size should be explored in other cohorts.

The strengths of this study primarily stem from its prospective cohort design, large size, and unique ability to link various population registries together for high-quality exposure and outcome assessments. Our study also benefits from state-of-the-art exposure modeling methods and information on residential noise exposure-an important, yet often unadjusted for, potential confounder of the association between air pollution and MI risk. We did not have data on out-of-hospital MI deaths for the final $1.5 \mathrm{y}$ of the study period because we did not have access to the DRCD after 31 December 2013. Further, we did not have data on revascularizations to construct a combined outcome. Given the observed special importance of air pollution on fatal MI outcomes, we hypothesize that this may have diluted the effect sizes of the estimates for fatal MIs.

Because of the missing exposure and covariate data, we excluded a substantial portion of the Danish Nurse Cohort in this study. Although we cannot exclude the possibility of selection bias, we do not have reason to believe that missingness on covariates or exposure was dependent on the outcome. Potential misclassification, both in outcome and exposure, are also limitations of this study. We were unable to obtain true personal exposures that accounted for commute or workplace air pollution levels and possible overlooked confounding by sources of indoor air pollution. Further, the likelihood of error in the exposure estimates during our study should not be ignored, and validations of our model in 1999 and 2009 suggest that it may have been less precise during the first half of our study (Hvidtfeldt et al. 2018). Given the relatively small values of the IQR exposure increments for $\mathrm{PM}_{2.5}\left(5.3 \mu \mathrm{g} / \mathrm{m}^{3}\right)$ and $\mathrm{PM}_{10}\left(5.5 \mu \mathrm{g} / \mathrm{m}^{3}\right)$ in this study, even small errors in exposure estimates could have significant implications for exposure misclassification. However, we believe that potential misclassification related to both air pollution modeling errors and the measurement of confounders will be random and tend to move the results toward the null hypothesis. Exposure misclassification was equally inevitable for residential traffic noise given that information on personal exposure modifiers such as nighttime earplug usage or insulation by window or other building materials could not be accounted for.

\section{Conclusion}

Evidence on long-term exposure to air pollution and incident MI is inconsistent, especially in light of the unknown contribution of road traffic noise. This prospective cohort study of 22,882 Danish female nurses $>44$ years of age is the first to examine the association between PM and incident MI adjusting for road traffic noise. We did not observe associations between $\mathrm{PM}_{2.5}, \mathrm{PM}_{10}, \mathrm{NO}_{2}$, or $\mathrm{NO}_{\mathrm{x}}$ with overall incident MI. However, we observed associations between $\mathrm{PM}_{2.5}$ and $\mathrm{PM}_{10}$ among a subset of fatal incident MI cases. Our findings were robust to adjustment for road traffic noise; however, further investigation is warranted.

\section{Acknowledgments}

This work was funded by a grant from Danish Council for Independent Research (DFF-4183-00353).

\section{References}

Atkinson RW, Carey IM, Kent AJ, van Staa TP, Anderson HR, Cook DG. 2013. Longterm exposure to outdoor air pollution and incidence of cardiovascular diseases. Epidemiology 24(1):44-53, PMID: 23222514, https://doi.org/10.1097/EDE. Ob013e318276ccb8.

Babisch W. 2014. Updated exposure-response relationship between road traffic noise and coronary heart diseases: a meta-analysis. Noise Health 16(68):1-9, PMID: 24583674, https://doi.org/10.4103/1463-1741.127847.

Bai L, Shin S, Burnett RT, Kwong JC, Hystad P, van Donkelaar A, et al. 2019a. Exposure to ambient air pollution and the incidence of congestive heart failure and acute myocardial infarction: a population-based study of 5.1 million Canadian adults living in Ontario. Environ Int 132:105004, PMID: 31387019, https://doi.org/10. 1016/j.envint.2019.105004.

Bai L, Weichenthal S, Kwong JC, Burnett RT, Hatzopoulou M, Jerrett M, et al. 2019b. Associations of long-term exposure to ultrafine particles and nitrogen dioxide with increased incidence of congestive heart failure and acute myocardial infarction. Am J Epidemiol 188(1):151-159, PMID: 30165598, https://doi.org/10.1093/ aje/kwy194.

Balti EV, Echouffo-Tcheugui JB, Yako YY, Kengne AP. 2014. Air pollution and risk of type 2 diabetes mellitus: a systematic review and meta-analysis. Diabetes Res Clin Pract 106(2):161-172, PMID: 25262110, https://doi.org/10.1016/j.diabres.2014. 08.010 .

Berkowicz R. 2000. OSPM-a parameterised street pollution model. Environ Monit Assess 65(1-2):323-331, https://doi.org/10.1023/A:1006448321977.

Bodin T, Björk J, Mattisson K, Bottai M, Rittner R, Gustavsson P, et al. 2016. Road traffic noise, air pollution and myocardial infarction: a prospective cohort study. Int Arch Occup Environ Health 89(5):793-802, PMID: 26867595, https://doi.org/10. 1007/s00420-016-1115-9.

Brandt J, Christensen JH, Frohn LM, Palmgren F, Berkowicz R, Zlatev Z. 2001. Operational air pollution forecasts from European to local scale. Atmos Environ 35(suppl 1):S91-S98, https://doi.org/10.1016/S1352-2310(00)00415-5.

Brandt J, Silver JD, Frohn LM, Geels C, Gross A, Hansen AB, et al. 2012. An integrated model study for Europe and North America using the Danish Eulerian Hemispheric Model with focus on intercontinental transport of air pollution. Atmos Environ 53:156-176, https://doi.org/10.1016/j.atmosenv.2012.01.011.

Brook RD, Franklin B, Cascio W, Hong Y, Howard G, Lipsett M, et al. 2004. Air pollution and cardiovascular disease: a statement for healthcare professionals from the expert panel on population and prevention science of the American Heart Association. Circulation 109(21):2655-2671, PMID: 15173049, https://doi.org/10. 1161/01.CIR.0000128587.30041.C8.

Brook RD, Rajagopalan S, Pope CA III, Brook JR, Bhatnagar A, Diez-Roux AV, et al. 2010. Particulate matter air pollution and cardiovascular disease: an update to the scientific statement from the American Heart Association. Circulation 121(21):2331-2378, PMID: 20458016, https://doi.org/10.1161/CIR.0b013e3181dbece1.

Coloma PM, Valkhoff VE, Mazzaglia G, Nielsson MS, Pedersen L, Molokhia M, et al. 2013. Identification of acute myocardial infarction from electronic healthcare records using different disease coding systems: a validation study in three 
European countries. BMJ Open 3(6):e002862, PMID: 23794587, https://doi.org/ 10.1136/bmjopen-2013-002862.

Danesh Yazdi M, Wang Y, Di Q, Zanobetti A, Schwartz J. 2019. Long-term exposure to $\mathrm{PM}_{2.5}$ and ozone and hospital admissions of Medicare participants in the southeast USA. Environ Int 130:104879, PMID: 31238267, https://doi.org/10.1016/ j.envint.2019.05.073.

DELTA (Danish Electronics Light \& Acoustics). 2001. Nordic Environmental Noise Prediction Methods, Nord2000, Direct.

DELTA. 2006. Nord 2000. Validation of the Propagation Model. AV 1117/06. https:// assets.madebydelta.com/assets/docs/share/Akustik/Nord2000_Validation_of_the_ Propagation Model AV 1117 06.pdf [accessed 27 April 2020].

Downward GS, van Nunen EJHM, Kerckhoffs J, Vineis P, Brunekreef B, Boer JMA, et al. 2018. Long-term exposure to ultrafine particles and incidence of cardiovascular and cerebrovascular disease in a prospective study of a Dutch cohort. Environ Health Perspect 126(12):127007, PMID: 30566375, https://doi.org/10.1289/ EHP3047.

Ellermann T, Nygaard J, Nøjgaard JK, Nordstrøm C, Brandt J, Christensen J, et al. 2020. The Danish Air Quality Monitoring Programme. Annual Summary for 2018. Scientific Report from DCE-Danish Centre for Environment and Energy. No. 360. https://dce2.au.dk/pub/SR360.pdf [accessed 27 April 2020].

Eze IC, Hemkens LG, Bucher HC, Hoffmann B, Schindler C, Künzli N, et al. 2015. Association between ambient air pollution and diabetes mellitus in Europe and North America: systematic review and meta-analysis. Environ Health Perspect 123(5):381-389, PMID: 25625876, https://doi.org/10.1289/ehp.1307823.

Faustini A, Rapp R, Forastiere F. 2014. Nitrogen dioxide and mortality: review and meta-analysis of long-term studies. Eur Respir J 44(3):744-753, PMID: 24558178, https://doi.org/10.1183/09031936.00114713.

Frohn LM, Christensen JH, Brandt J. 2002. Development of a high-resolution nested air pollution model: the numerical approach. J Comput Phys 179(1):68-94, https://doi.org/10.1006/jcph.2002.7036.

Grazuleviciene R, Maroziene L, Dulskiene V, Malinauskiene V, Azaraviciene A, Laurinaviciene D, et al. 2004. Exposure to urban nitrogen dioxide pollution and the risk of myocardial infarction. Scand J Work Environ Health 30(4):293-298, PMID: 15458012, https://doi.org/10.5271/sjweh.797.

Griffin BA, Anderson GL, Shih RA, Whitsel EA. 2012. Use of alternative time scales in Cox proportional hazard models: implications for time-varying environmental exposures. Stat Med 31(27):3320-3327, PMID: 22531976, https://doi.org/10.1002/ sim.5347.

Heinonen-Guzejev M, Vuorinen HS, Mussalo-Rauhamaa H, Heikkilä K, Koskenvuo M, Kaprio J. 2007. The association of noise sensitivity with coronary heart and cardiovascular mortality among Finnish adults. Sci Total Environ, PMID: 17129598, https://doi.org/10.1016/j.scitotenv.2006.08.048.

Helweg-Larsen K. 2011. The Danish Register of Causes of Death. Scand J Public Health 39(suppl 7):26-29, PMID: 21775346, https://doi.org/10.1177/1403494811399958.

Héritier H, Vienneau D, Foraster M, Eze IC, Schaffner E, de Hoogh K, et al. 2019. A systematic analysis of mutual effects of transportation noise and air pollution exposure on myocardial infarction mortality: a nationwide cohort study in Switzerland. Eur Heart J 40(7):598-603, PMID: 30357335, https://doi.org/10.1093/ eurhearti/ehy650.

Hoek G, Brunekreef B, Goldbohm S, Fischer P, van den Brandt PA. 2002. Association between mortality and indicators of traffic-related air pollution in the Netherlands: a cohort study. Lancet 360(9341):1203-1209, PMID: 12401246, https://doi.org/10. 1016/S0140-6736(02)11280-3.

Hoffmann B, Weinmayr G, Hennig F, Fuks K, Moebus S, Weimar C, et al. 2015. Air quality, stroke, and coronary events: results of the Heinz Nixdorf Recall Study from the Ruhr region. Dtsch Arztebl Int 112(12):195-201, PMID: 25838021, https://doi.org/10.3238/arztebl.2015.0195.

Hundrup YA, Simonsen MK, Jørgensen T, Obel EB. 2012. Cohort profile: the Danish Nurse Cohort. Int J Epidemiol 41(5):1241-1247, PMID: 21421694, https://doi.org/ 10.1093/ije/dyr042.

Hvidtfeldt UA, Ketzel M, Sørensen M, Hertel 0, Khan J, Brandt J, et al. 2018. Evaluation of the Danish AirGIS air pollution modeling system against measured concentrations of $\mathrm{PM}_{2.5}, \mathrm{PM}_{10}$, and black carbon. Environ Epidemiol 2(2): e014, https://doi.org/10.1097/EE9.0000000000000014.

Jensen SS, Berkowicz R, Sten Hansen H, Hertel 0. 2001. A Danish decisionsupport GIS tool for management of urban air quality and human exposures. Transp Res D Transp Environ 6(4):229-241, https://doi.org/10.1016/S1361-9209 (00)00026-2.

Jensen SS, Ketzel M, Becker T, Christensen J, Brandt J, Plejdrup M, et al. 2017. High resolution multi-scale air quality modelling for all streets in Denmark. Transp Res D Transp Environ 52(pt A):322-339, https://doi.org/10.1016/j.trd.2017. 02.019 .

Joensen AM, Jensen MK, Overvad K, Dethlefsen C, Schmidt E, Rasmussen L, et al. 2009. Predictive values of acute coronary syndrome discharge diagnoses differed in the Danish National Patient Registry. J Clin Epidemiol 62(2):188-194, PMID: 18722087, https://doi.org/10.1016/j.jclinepi.2008.03.005.
Kaufman JD, Adar SD, Barr RG, Budoff M, Burke GL, Curl CL, et al. 2016. Association between air pollution and coronary artery calcification within six metropolitan areas in the USA (the Multi-Ethnic Study of Atherosclerosis and Air Pollution): a longitudinal cohort study. Lancet 388(10045):696-704, PMID: 27233746, https://doi.org/10.1016/S0140-6736(16)00378-0.

Ketzel M, Jensen SS, Brandt J, Ellermann T, Olesen H, Berkowicz R, et al. 2012. Evaluation of the street pollution model OSPM for measurements at 12 streets stations using a newly developed and freely available evaluation tool. J Civil Environ Eng S1:004, https://doi.org/10.4172/2165-784X.S1-004.

Khan J, Kakosimos K, Raaschou-Nielsen 0, Brandt J, Jensen SS, Ellermann T, et al. 2019. Development and performance evaluation of new AirGIS—a GIS based air posllution and human exposure modelling system. Atmos Environ 198:102121, https://doi.org/10.1016/j.atmosenv.2018.10.036.

Klompmaker JO, Hoek G, Bloemsma LD, Wijga AH, van den Brink C, Brunekreef B, et al. 2019. Associations of combined exposures to surrounding green, air pollution and traffic noise on mental health. Environ Int 129:525-537, PMID: 31158598, https://doi.org/10.1016/j.envint.2019.05.040.

Korn EL, Graubard BI, Midthune D. 1997. Time-to-event analysis of longitudinal follow-up of a survey: choice of the time-scale. Am J Epidemiol 146(1):528-529, PMID: 8982025, https://doi.org/10.1093/oxfordjournals.aje.a009034.

Künzli N, Jerrett M, Garcia-Esteban R, Basagaña X, Beckermann B, Gilliland F, et al. 2010. Ambient air pollution and the progression of atherosclerosis in adults. PLoS One 5(3):e9096, PMID: 20161713, https://doi.org/10.1371/journal.pone.0009096.

Lelieveld J, Klingmüller K, Pozzer A, Pöschl U, Fnais M, Daiber A, et al. 2019. Cardiovascular disease burden from ambient air pollution in Europe reassessed using novel hazard ratio functions. Eur Heart J 40(20):1590-1596, PMID: 30860255, https://doi.org/10.1093/eurheartj/ehz135.

Lipsett MJ, Ostro BD, Reynolds P, Goldberg D, Hertz A, Jerrett M, et al. 2011. Longterm exposure to air pollution and cardiorespiratory disease in the California Teachers Study cohort. Am J Respir Crit Care Med 184(7):828-835, PMID: 21700913, https://doi.org/10.1164/rccm.201012-20820C.

Lucht S, Hennig F, Moebus S, Führer-Sakel D, Herder C, Jöckel KH, et al. 2019. Air pollution and diabetes-related biomarkers in non-diabetic adults: a pathway to impaired glucose metabolism? Environ Int 124:370-392, PMID: 30660850, https://doi.org/10.1016/j.envint.2019.01.005.

Madrigano J, Kloog I, Goldberg R, Coull BA, Mittleman MA, Schwartz J. 2013. Long-term exposure to $\mathrm{PM}_{2.5}$ and incidence of acute myocardial infarction Environ Health Perspect 121(2):192-196, PMID: 23204289, https://doi.org/10. 1289/ehp.1205284.

Madsen M, Davidsen M, Rasmussen S, Abildstrom SZ, Osler M. 2003. The validity of the diagnosis of acute myocardial infarction in routine statistics: a comparison of mortality and hospital discharge data with the Danish MONICA registry. J Clin Epidemiol 56(2):124-130, PMID: 12654406, https://doi.org/10.1016/S08954356(02)00591-7.

Mann JK, Tager IB, Lurmann F, Segal M, Quesenberry CP Jr, Lugg MM, et al. 2002. Air pollution and hospital admissions for ischemic heart disease in persons with congestive heart failure or arrhythmia. Environ Health Perspect 110(12):1247-1252, PMID: 12460805, https://doi.org/10.1289/ehp.021101247.

Miller KA, Siscovick DS, Sheppard L, Shepherd K, Sullivan JH, Anderson GL, et al. 2007. Long-term exposure to air pollution and incidence of cardiovascular events in women. N Engl J Med 356(5):447-458, PMID: 17267905, https://doi.org/ 10.1056/NEJMoa054409.

Pedersen CB. 2011. The Danish Civil Registration System. Scand J Public Health 39(suppl 7):22-25, PMID: 21775345, https://doi.org/10.1177/1403494810387965.

Pope CA III, Burnett RT, Thurston GD, Thun MJ, Calle EE, Krewski D, et al. 2004. Cardiovascular mortality and long-term exposure to particulate air pollution: epidemiological evidence of general pathophysiological pathways of disease. Circulation 109(1):71-77, PMID: 14676145, https://doi.org/10.1161/01.CIR.0000108927. 80044.7F.

Puett RC, Hart JE, Suh H, Mittleman M, Laden F. 2011. Particulate matter exposures, mortality, and cardiovascular disease in the Health Professionals Follow-Up Study. Environ Health Perspect 119(8):1130-1135, PMID: 21454146, https://doi.org/10.1289/ehp.1002921.

Puett RC, Hart JE, Yanosky JD, Paciorek C, Schwartz J, Suh H, et al. 2009. Chronic fine and coarse particulate exposure, mortality, and coronary heart disease in the Nurses' Health Study. Environ Health Perspect 117(11):1697-1701, PMID: 20049120, https://doi.org/10.1289/ehp.0900572.

Puett RC, Schwartz J, Hart JE, Yanosky JD, Speizer FE, Suh H, et al. 2008. Chronic particulate exposure, mortality, and coronary heart disease in the Nurses' Health Study. Am J Epidemiol 168(10):1161-1168, PMID: 18835862, https://doi.org/ 10.1093/aje/kwn232.

Rosenlund M, Bellander T, Nordquist T, Alfredsson L. 2009. Traffic-generated air pollution and myocardial infarction. Epidemiology 20(2):265-271, PMID: 19096356, https://doi.org/10.1097/EDE.0b013e318190ea68.

Rosenlund M, Berglind N, Pershagen G, Hallqvist J, Jonson T, Bellander T. 2006. Long-term exposure to urban air pollution and myocardial infarction. 
Epidemiology 17(4):383-390, PMID: 16699471, https://doi.org/10.1097/01.ede. 0000219722.25569.0f.

Roswall N, Raaschou-Nielsen 0, Ketzel M, Gammelmark A, Overvad K, Olsen A, et al. 2017. Long-term residential road traffic noise and $\mathrm{NO}_{2}$ exposure in relation to risk of incident myocardial infarction-a Danish cohort study. Environ Res 156:80-86, PMID: 28334645, https://doi.org/10.1016/j.envres.2017.03.019.

Selander J, Bluhm G, Nilsson M, Hallqvist J, Theorell T, Willix P, et al. 2013. Joint effects of job strain and road-traffic and occupational noise on myocardial infarction. Scand J Work Environ Health 39(2):195-203, PMID: 23032870, https://doi.org/ $10.5271 /$ sjweh.3324.

Shin J, Choi J, Kim KJ. 2019. Association between long-term exposure of ambient air pollutants and cardiometabolic diseases: a 2012 Korean Community Health Survey. Nutr Metab Cardiovasc Dis 29(2):144-151, PMID: 30595346, https://doi.org/ 10.1016/.j.numecd.2018.09.008.

Stockfelt L, Andersson EM, Molnár P, Rosengren A, Wilhelmsen L, Sallsten G, et al. 2015. Long term effects of residential $\mathrm{NO}_{\mathrm{x}}$ exposure on total and cause-specific mortality and incidence of myocardial infarction in a Swedish cohort. Environ Res 142:197-206, PMID: 26163761, https://doi.org/10.1016/j.envres.2015.06.045.

Sundbøll J, Adelborg K, Munch T, Frøslev T, Sørensen HT, Bøtker HE, et al. 2016. Positive predictive value of cardiovascular diagnoses in the Danish National Patient Registry: a validation study. BMJ Open 6(11):e012832, PMID: 27864249, https://doi.org/10.1136/bmjopen-2016-012832.

Sun Q, Wang A, Jin X, Natanzon A, Duquaine D, Brook RD, et al. 2005. Long-term air pollution exposure and acceleration of atherosclerosis and vascular inflammation in an animal model. JAMA 294(23):3003-3010, PMID: 16414948, https://doi.org/10. 1001/jama.294.23.3003.

Sun Q, Yue P, Deiuliis JA, Lumeng CN, Kampfrath T, Mikolaj MB, et al. 2009. Ambient air pollution exaggerates adipose inflammation and insulin resistance in a mouse model of diet-induced obesity. Circulation 119(4):538-546, PMID: 19153269, https://doi.org/10.1161/CIRCULATIONAHA.108.799015.

Thygesen SK, Christiansen CF, Christensen S, Lash TL, Sørensen HT. 2011. The predictive value of ICD-10 diagnostic coding used to assess Charlson comorbidity index conditions in the population-based Danish National Registry of Patients. BMC Med Res Methodol 11:83, PMID: 21619668, https://doi.org/10.1186/1471-2288-11-83.

WHO (World Health Organization). 1966. International Statistical Classification of Diseases and Related Health Problems, 8th Revision. Geneva, Switzerland: WHO.

WH0. 2016. International Statistical Classification of Diseases and Related Health Problems, 10th Revision. http://apps.who.int/classifications/icd10/browse/2016/ en [accessed 28 April 2020].

Xu H, Wang T, Liu S, Brook RD, Feng B, Zhao Q, et al. 2019. Extreme levels of air pollution associated with changes in biomarkers of atherosclerotic plaque vulnerability and thrombogenicity in healthy adults: the Beijing AIRCHD study. Circ Res 124(5):e30-e43, PMID: 30661461, https://doi.org/10.1161/CIRCRESAHA.118.313948.

Yusuf S, Joseph P, Rangarajan S, Islam S, Mente A, Hystad P, et al. 2020. Modifiable risk factors, cardiovascular disease, and mortality in 155722 individuals from 21 high-income, middle-income, and low-income countries (PURE): a prospective cohort study. Lancet 395(10226):795-808, PMID: 31492503, https://doi.org/10.1016/ S0140-6736(19)32008-2. 